\title{
Spatial variation of the stress field along the fault rupture zone of the 1999 Izmit earthquake
}

\author{
A. P nar ${ }^{1}$, S. B. Üçer ${ }^{3}$, Y. Honkura ${ }^{2}$, N. Sezgin ${ }^{1}$, A. Ito $^{4}$, Ş. Bar ş ${ }^{5}$, D. Kalafat ${ }^{3}$, M. Matsushima ${ }^{2}$, and S. Horiuchi ${ }^{6}$ \\ ${ }^{1}$ Department of Geophysics, Istanbul University, 34850, Avcilar, Istanbul, Turkey \\ ${ }^{2}$ Department of Earth and Planetary Sciences, Tokyo Institute of Technology, Tokyo 152-8551, Japan \\ ${ }^{3}$ Kandilli Observatory and Earthquake Research Institute, Boğaziçi University, Çengelköy, İstanbul, Turkey \\ ${ }^{4}$ Faculty of Education, Utsunomiya University, Utsunomiya 321-8505, Japan \\ ${ }^{5}$ Department of Geophysics, Kocaeli University, 41380, Umuttepe, İzmit, Turkey \\ ${ }^{6}$ National Research Institute for Earth Science and Disaster Prevention, Tsukuba 305-0006, Japan
}

(Received February 3, 2009; Revised November 5, 2009; Accepted December 9, 2009; Online published March 4, 2010)

\begin{abstract}
We have investigated the spatial variation of the stress eld along the fault rupture zone of the 1999 Izmit earthquake $\left(M_{\mathrm{w}}\right.$ 7.4) using rst-motion polarity data at seven distinct aftershock clusters. In our approach, the rst-motion polarities of all the aftershocks in a cluster are simultaneously inverted to determine the stress tensor parameters and fault plane solutions of individual events, in accordance with the method of Horiuchi et al. (1995). Where post-seismic slip was signi cant (e.g., Sapanca, Sakarya-Akyaz, and Karadere segments), we obtained stress tensors with the fault parallel or fault normal maximum $\left(\sigma_{1}\right)$ and minimum $\left(\sigma_{3}\right)$ principal compressive stress axes, which may imply either low frictional coef cients or fault weakness. A stress tensor with similar features was derived from the Ç narc $\mathrm{k}$ cluster, where the aftershocks lie in a low-velocity zone beneath the geothermal area. The maximum principal stress axis tends to remain parallel to the trend of the pre-mainshock $\sigma_{1}$ around the Yalova segment; this segment experienced little to no co-seismic displacements. The stress tensor around the Gölcük segment, where the largest surface displacement of $5.5 \mathrm{~m}$ was observed, was determined to be $20-25^{\circ}$ counterclockwise rotated, but the aftershock alignment remained fault parallel. We interpret these results in terms of the strong crust. On the other hand, both the aftershock alignment and the stress tensor were found to be rotated in the Izmit earthquake epicentral region despite the lower co-seismic displacements. We attribute this feature to the weak crust.
\end{abstract}

Key words: Izmit earthquake, aftershocks, stress tensor, focal mechanism.

\section{Introduction}

The 1500-km-long North Anatolian Fault zone (NAFZ) accommodating the translation and counterclockwise rotation between the Anatolian and the Eurasian plates (Fig. 1) is comprised of several fault segments. Most of these were ruptured at different times during the twentieth century by major $\left(M_{\mathrm{w}} 7\right)$ earthquakes (Barka and Kadinsky-Cade, 1988; Barka, 1992, 1996; Stein et al., 1997; McClusky et al., 2000). The segmentation of such large strike-slip faults generates complex earthquakes associated with failure on several segments. For example, the 1992 Landers earthquake $\left(M_{\mathrm{w}} 7.3\right)$ ruptured ve distinct fault segments with different geometries separated by releasing and restraining step-overs (Sieh et al., 1993). This multi-segment rupture pattern is a characteristic feature of the large NAFZ earthquakes generating complex waveforms and has been observed in the 1992 Erzincan $\left(M_{\mathrm{w}} 6.8\right)$ and 1967 Mudurnu Valley $\left(M_{\mathrm{w}} 7.1\right)$ earthquakes (P nar et al., 1994, 1996; Barka, 1996) and, most recently, in the 1999 Izmit and Düzce earthquakes (Gülen et al., 2002; Utkucu et al., 2003).

Copyright (C) The Society of Geomagnetism and Earth, Planetary and Space Sciences (SGEPSS); The Seismological Society of Japan; The Volcanological Society of Japan; The Geodetic Society of Japan; The Japanese Society for Planetary Sciences; TERRAPUB.

doi:10.5047/eps.2009.12.001
The 17 August 1999 Izmit earthquake $\left(M_{\mathrm{w}} 7.4\right)$ ruptured four distinct strike-slip fault segments with a right-lateral sense of motion separated by step-over basins of different sizes (Çemen et al., 2000; Ayd n and Kalafat, 2002; Barka et al., 2002; Gülen et al., 2002; Lettis et al., 2002). The orientation, length, and measured offsets on these fault segments were not uniform, but the sense of motion was predominantly right-lateral strike-slip. The orientation of the western-most 30-km-long Gölcük segment, where 4- to 5.5$\mathrm{m}$ surface rupture displacements were observed, varies from $\mathrm{N} 78^{\circ} \mathrm{E}$ to $\mathrm{N} 84^{\circ} \mathrm{E}$, while the average offset on the $26-\mathrm{km}$ long, $\mathrm{N} 89^{\circ} \mathrm{W}$-oriented Sapanca segment was between 2 and $3 \mathrm{~m}$ (Çemen et al., 2000; Lettis et al., 2002). The maximum displacement on the $\mathrm{N} 87^{\circ} \mathrm{W}$-oriented, 36-km-long Sakarya segment was $5 \mathrm{~m}$, with an average of 2-4 $\mathrm{m}$, and the minimum offset (1-1.5 m) was measured on the easternmost $35-\mathrm{km}$-long Karadere fault segment that is oriented from $\mathrm{N} 50^{\circ} \mathrm{E}$ to $\mathrm{N} 80^{\circ} \mathrm{E}$ (Lettis et al., 2002). A recent study based on high-resolution bathymetry data provides strong evidence showing that no signi cant motion occurred on the 40-km-long offshore Yalova segment located to the west of the Gölcük segment (Cormier et al., 2006), though modeling of geophysical data suggests considerable displacements (Wright et al., 2001; Gülen et al., 2002).

The right or left step-over of the segments on the NAFZ 


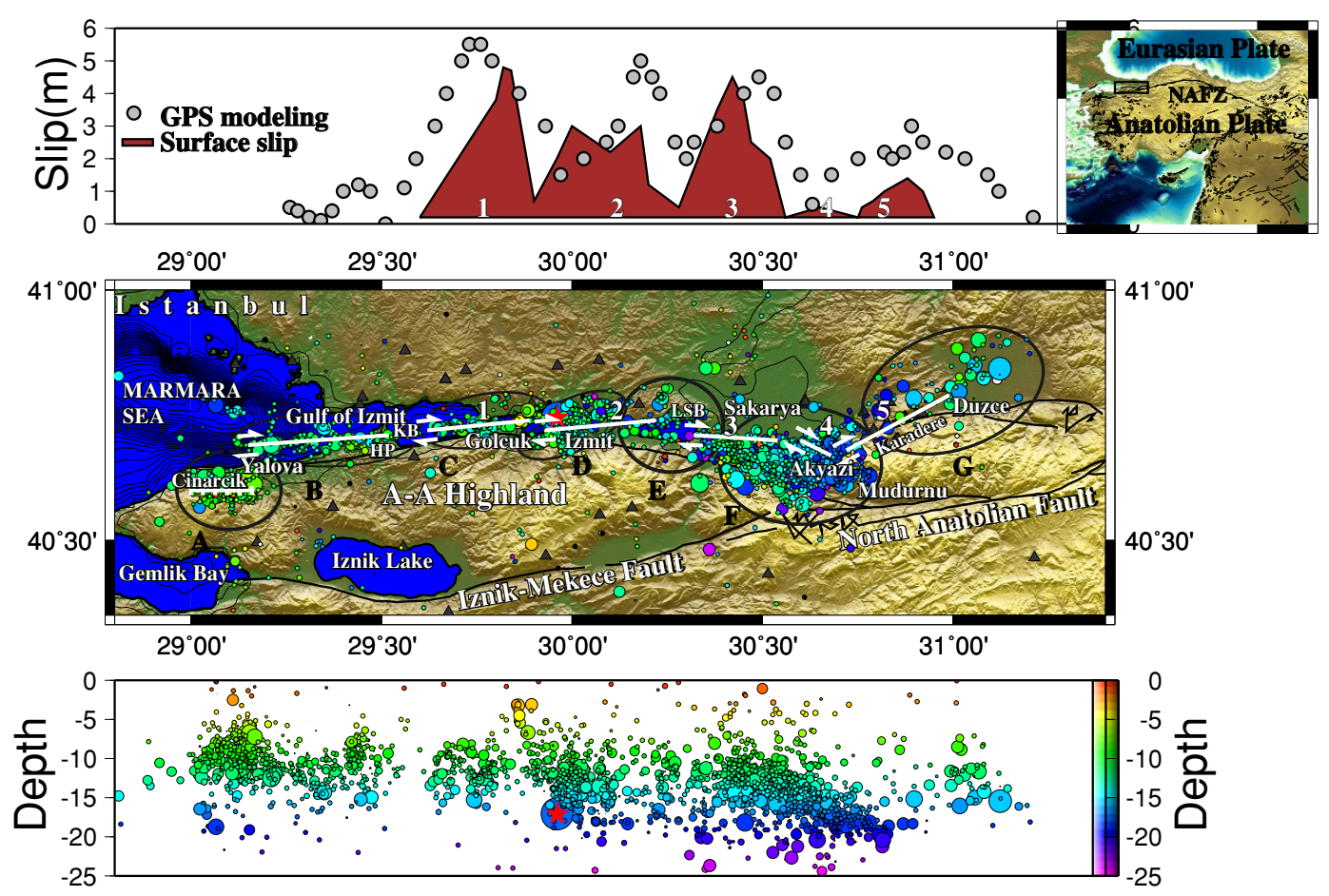

Fig. 1. Aftershock activity from 17 August 1999 to 16 October 1999 depicting the fault rupture zone of the Izmit earthquake (Ito et al., 2002). The star indicates the hypocenter of the mainshock. The capital letters A-G are used to name the cluster zones (A, Çınarcık; B, Yalova; C, Gölcük; D, İzmit; E, Sapanca; F, Sakarya-Akyazi; G, Karadere). KB, Karamursel basin; HP, Hersek peninsula; LSB, Lake Sapanca basin. The location names mentioned in the text are also shown. The surface slip data associated with the fault segments are numbered from 1 to 5 and originate from Aydın and Kalafat (2002). The upper dotted line indicates the co-seismic slip model for the mainshock based on GPS data (Reilinger et al., 2000). The upper right corner of the figure shows the Eurasian and Anatolian plates and the trace of the North Anatolian Fault Zone (NAFZ).

results in releasing or restraining bends and the development of step-over basins (Barka and Kadinsky-Cade, 1988). The right step-over of the Gölcük segment to the Yalova segment created the 5-km-wide Karamürsel basin that arrested 4- to 5-m co-seismic displacements on the Gölcük segment and prevented major failure on the Yalova segment (Lettis et al., 2002; Cormier et al., 2006). On the other hand, the ruptures on the Gölcük segment propagated eastward through the 1- to 2-km-wide Gölcük step-over basin, triggering 2- to 3-m surface displacements on the Sapanca segment (Çemen et al., 2000; Aydın and Kalafat, 2002; Barka et al., 2002; Gülen et al., 2002). Furthermore, the ruptures on the Sapanca segment propagated further east through the 1- to 2-km-wide Lake Sapanca basin that is created by the right step-over of the Sakarya segment to the Sapanca segment (Langridge et al., 2002; Lettis et al., 2002). The Karamürsel, Gölcük, and Sapanca stepover basins are the releasing bends where normal faults are prominent features. In comparison, the left step-over of the Karadere segment to the Sakarya segment creates a restraining bend where the highest aftershock activity took place. In the study reported here, we show that the aftershock activity is not in conjunction with the restraining bend; rather, it reflects stress perturbations in a large releasing area bounded in the south by the faults ruptured by the 1967 Mudurnu Valley earthquake and in the north by the faults ruptured by the 1999 Izmit earthquake.

In this study, we determine the focal mechanisms of aftershocks that took place on these fault segments or within the step-over basins, which were either ruptured or acti- vated by the mainshock generating distinct clusters of aftershocks. The fault plane solutions and the stress tensors derived for the clusters reflect the responses of the faults to the co-seismic ruptures; these ruptures depend primarily on the crustal rheology and the state of stress prior to the mainshock. We first determine the pre-mainshock regional stress tensors, using the focal mechanisms of large events located in the proximity of the source region, and then compare the regional and the local stress tensors, with the aim of gaining an understanding of the causes of deviations between these. In the following sections, we argue, taking into account the results of previous studies, that a careful examination of a local stress tensor derived from an aftershock swarm provides valuable clues on the fault friction coefficient (fault strength), the state of stress prior to a mainshock, the strength of the crust, and/or the post-seismic slip.

\section{Regional Stress Tensor in the Source Region of the 1999 Izmit Earthquake}

The principal objective of our study is to compare the regional stress tensor in the region between Yalova and Düzce with the local stress tensors derived from the aftershock clusters lying along the fault rupture zone (Fig. 1). A likely cause for the discrepancy in the orientation between the local stress tensors and the regional stress tensor could be either the source process of the mainshock or spatial variations in crustal rheology. Therefore, we first estimate a regional stress tensor using the fault plane solutions of large events given in Eyidoğan et al. (1991) and the 
(a)

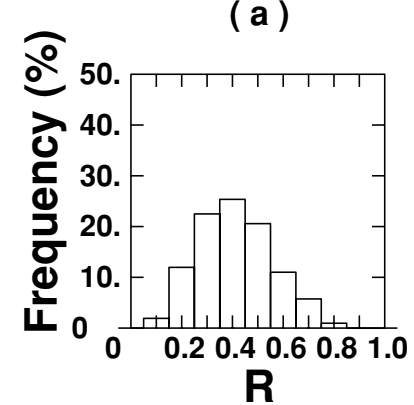

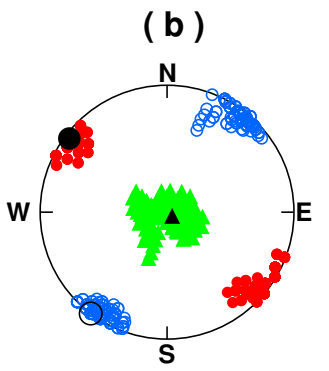

(b) (c)

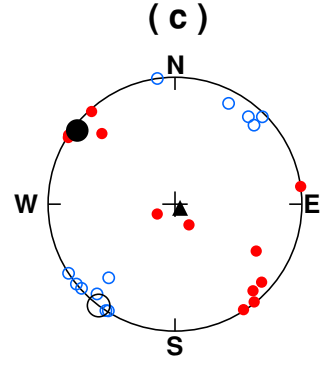

Fig. 2. The results of the stress tensor analysis for the $P$ - and $T$-axes of the focal mechanisms of large earthquakes that occurred in the source region since 1943. (a) The histogram of the $R$-value, (b) the distribution of the estimated principal stress axes, and (c) the distribution of the observed $P$ - and $T$-axes. In (b), red solid dots show the azimuth and plunge of the maximum compression axis $\sigma_{1}$, blue circles show those of the minimum stress axis $\sigma_{3}$, green triangles show those of the intermediate stress axis $\sigma_{2}$. In (c), red solid dots show the $P$-axes and blue circles the $T$-axes. Black symbols denote the axes for the best stress model.

Harvard CMT catalogue.

The method we use to derive the stress tensor is described in Gephart and Forsyth (1984). Input data for stress tensor inversion is the orientation of the $P$ - and $T$-axes of fault plane solutions. The method yields a stress tensor defined by three principal stress components, namely, maximum compression $\left(\sigma_{1}\right)$, intermediate compression $\left(\sigma_{2}\right)$, and minimum compression $\left(\sigma_{3}\right)$, with the stress magnitude ratio defined as $R=\left(\sigma_{2}-\sigma_{1}\right) /\left(\sigma_{3}-\sigma_{1}\right)$. The value of $R$ is a measure used to characterize the stress field. For example, $R \approx 0$ when $\sigma_{1} \approx \sigma_{2}$ (biaxial deviatoric compression or state of confined extension), $R \approx 1$ when $\sigma_{2} \approx \sigma_{3}$ (uniaxial deviatoric compression or state of confined compression), and $R \approx 0.5$ when $\sigma_{1} \approx \sigma_{2} \approx \sigma_{3}$ (triaxial compression). More detailed explanations on $R$ are given by Bellier and Zoback (1995). In a strike-slip faulting stress regime where $\sigma_{1}$ and $\sigma_{3}$ are horizontal and $\sigma_{2}$ is vertical $\left(\sigma_{1}=\sigma_{H \max }, \sigma_{3}=\sigma_{h \min }, \sigma_{2}=\sigma_{v} ; \sigma_{H \max }=\right.$ maximum horizontal stress, $\sigma_{v}=$ vertical stress, and $\sigma_{h \min }=$ minimum horizontal stress), the stress ratio $R \approx 1$ represents the transition from a strike-slip to reverse faulting stress regime (in which $\sigma_{h \min } \approx \sigma_{v}$ ).

The combination of the four parameters $\left(\sigma_{1}, \sigma_{2}, \sigma_{3}\right.$, and $R$ ) is called a stress model, and the model that most closely matches the whole observed data set is called the bestfitting stress model. The best-fitting model is searched for in a grid over the four model parameters, systematically adjusting each parameter one at a time through a wide range of possibilities (Gephart and Forsyth, 1984). The measure of misfit is given by the smallest rotation about an axis of any orientation that brings one of the nodal planes and the slip direction into an orientation consistent with the stress model.

If the fault plane of a focal mechanism is known (for example, from surface ruptures), it can be a priori information for stress tensor inversion. The amount of data we use here to derive a stress tensor is limited, but surface ruptures were observed in six of 12 events used in the calculations. These are the 1957 Abant $\left(M_{\mathrm{w}}=7.0\right)$ earthquake, the three major subevents of the 1967 Mudurnu $\left(M_{\mathrm{w}}=7.2\right)$ earthquake obtained by Pinar et al. (1996), and the 1999 Izmit $\left(M_{\mathrm{w}}=7.4\right)$ and the 1999 Düzce $\left(M_{\mathrm{w}}=7.2\right)$ earthquakes. We have not included the focal mechanisms of aftershocks in the stress tensor inversion in view of the fact that the displacements on the faults perturb the stress field generating the aftershocks. The major events in the region are characterized by predominantly right-lateral strike-slip faulting with nearly E-W striking fault planes, implying a roughly NW-SE-oriented horizontal maximum principal stress axis $\left(\sigma_{1}\right)$ and a NE-SW striking horizontal minimum compressive stress axis $\left(\sigma_{3}\right)$. We use that piece of information as an initial stress model to invert focal mechanism data. The inversion yielded the best stress tensor, with azimuth and plunge values of $\sigma_{1}=(307,4), \sigma_{2}=(91,86)$, and $\sigma_{3}=(217,0)$ and a stress amplitude ratio $R=0.4$, indicating tri-axial compression. These values are close to the ones obtained by Kiratzi (2002) although her data includes several aftershocks. The measure of the goodness of the solution is the average misfit rotation angle, which we found to be $2.0^{\circ}$. Such a low average misfit error reflects the stress homogeneity and shows how well the individual focal mechanisms fit the derived stress tensor. The low and large misfit angles indicate homogeneous and heterogeneous stress fields, respectively. The histogram of $R$ values, the stress tensor models predicted within the $95 \%$ confidence limit, and the observed $P$ - and $T$-axes are shown in Fig. 2(a, b and c, respectively).

\section{Stress Tensor Inversion Based on First Motion Polarities of Aftershocks}

Horiuchi et al. (1995) developed a method that uses firstmotion $P$-wave polarity data for the simultaneous determination of stress tensor and fault plane solutions of earthquakes. Here we provide a brief explanation of the method; for more details, the reader is referred to Horiuchi et al. (1995).

The method is based on estimating the number of inconsistent polarities between the observed and theoretical amplitude of the $P$-waves of events taking place within the same stress regime at various seismic station. The theoretical amplitude is calculated as a function of the orientation of the principal stress axes and the fault plane parameters, i.e., the number of inconsistent data points is a function of the stress tensor and the fault plane parameters. The best fit solution is obtained when the number of the inconsistent observed polarities reaches the minimum. To 


\section{Frequency Distribution of First Motion Polarities}

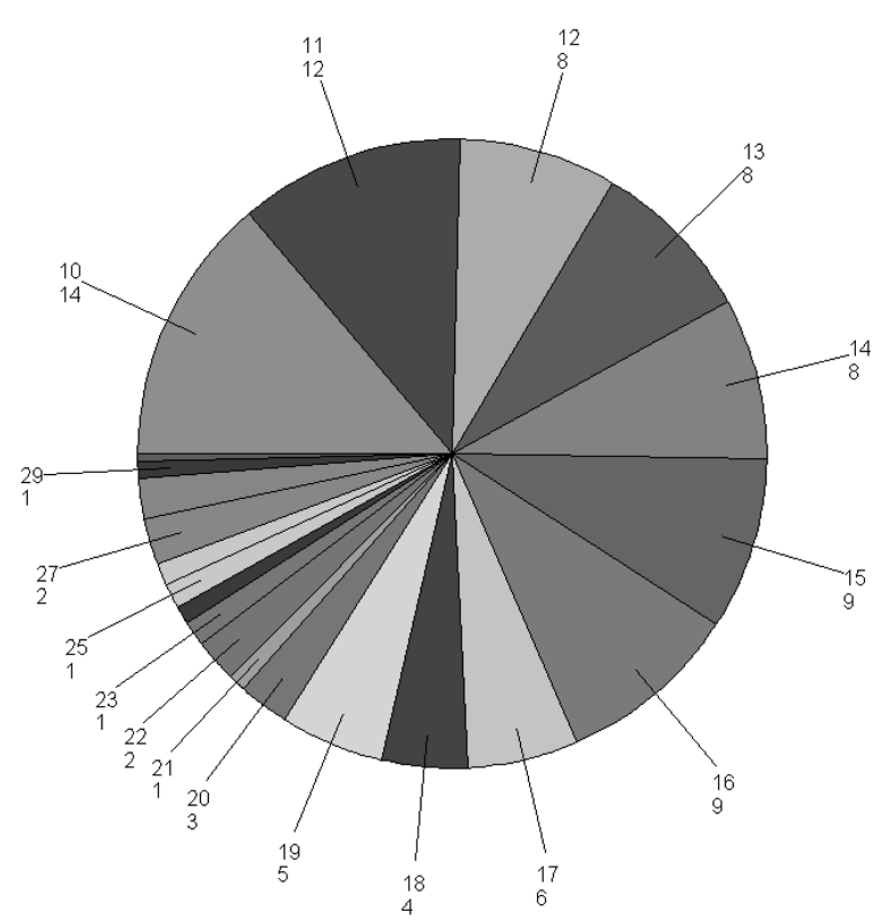

Fig. 3. Frequency distribution of first-motion polarity data. The upper number is the number of observed polarity in an aftershock, and the lower number its frequency in the whole data set.

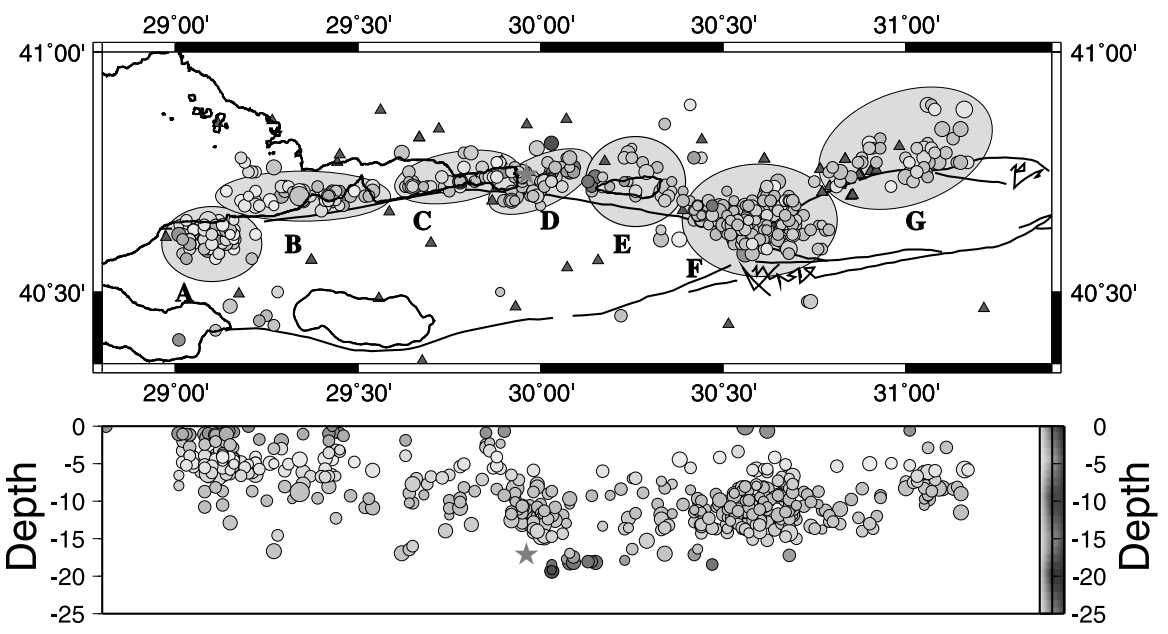

Fig. 4. The location of the aftershocks and the clusters for which focal mechanisms and stress tensor are determined simultaneously using first-motion polarity data.

achieve the latter we first determine-for each event- the number of inconsistent stations for all cases of the theoretical focal mechanisms calculated with intervals of certain degrees. This calculation is performed for all of the observed events, and all of the calculated values are stored in a file. Using these stored data, we then determine the parameters of the stress tensor for which the number of the inconsistent stations is minimum. In this step, the locations of the plunge and azimuth for which the number of misfit polarity is the minimum are determined by allowing for the principal stresses in all directions with a certain interval and making a grid search against the other unknown parameters
(Horiuchi et al., 1995). Also, based on our assumption that the slip direction is parallel to the direction of maximum shear stress, the method can distinguish the fault plane from the two nodal planes.

Our data set includes the first-motion polarities of 758 aftershocks of the August 17, 1999 Izmit earthquake (Fig. 1). The larger $\left(M_{\mathrm{w}}>4\right)$ aftershocks have been previously studied using moment tensor inversion techniques (Örgülü and Aktar, 2001; Pinar et al., 2001, 2003). Here, we analyze aftershocks with magnitudes $M_{\mathrm{w}}<4.0$. Because of the smaller size of the aftershocks and the sparse seismic network, almost half of the aftershocks were recorded at fewer 

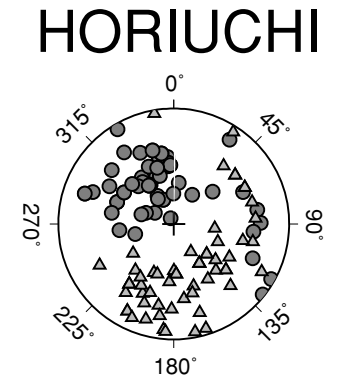

FPFIT

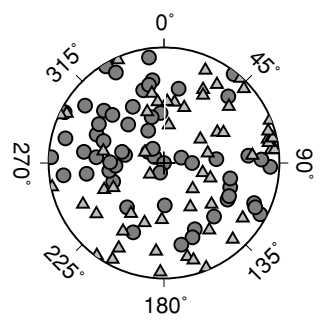

Fig. 5. The lower hemisphere projection of the $P$ - and $T$-axes of focal mechanism of events determined using the method of Horiuchi et al. (1995) and the FPFIT program of Reasenberg and Oppenheimer (1985).
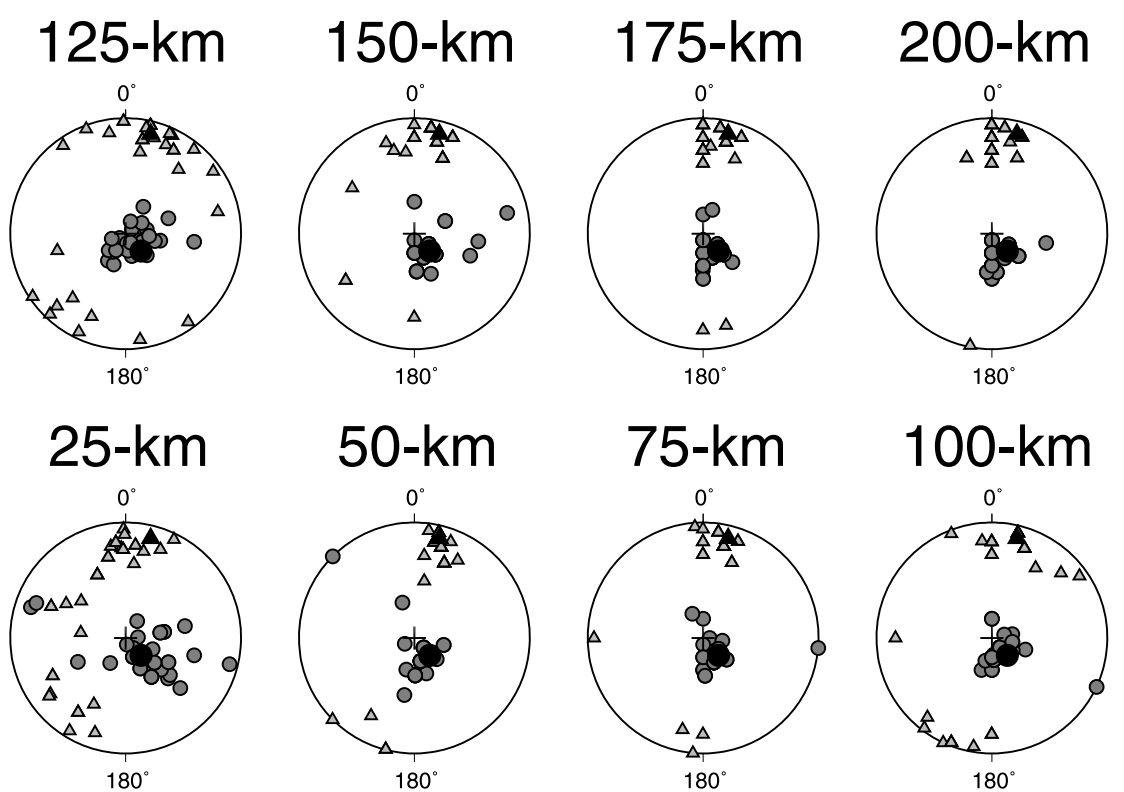

Fig. 6. The lower hemisphere projection of the $P$ - and $T$-axes of the focal mechanism of 34 theoretical events, each consisting of ten first-motion polarities which were inverted for focal mechanisms using the method of Horiuchi et al. (1995). The solid dots are the locations of the estimated $P$-axes, the triangles are those of the $T$-axes. The large solid dot and triangle are the $P$ - and $T$-axis, respectively, of the focal mechanism that was used to generate the theoretical data set. The maximum epicentral distance used for generating the data sets is shown above the spheres.

than 15 seismic stations, and $14 \%$ of them were recorded at just ten seismic stations (Fig. 3). Even with a good crustal model it is hard to constrain the focal mechanism of an event with ten-polarity data. Using the well-known FPFIT routine (Reasenberg and Oppenheimer, 1985), we first attempted to determine the focal mechanism of aftershock clusters shown in Fig. 4 and found out that most of these events have multiple solutions, i.e., several focal mechanisms explain equally well the observations that have a low number of polarity events.

Using this condition and the method of Horiuchi et al. (1995), we show that although the first-motion polarity data of individual events poorly constrain the focal mechanism solutions, a cluster of such events better constrains the faulting parameters when polarity data of these events are simultaneously used to derive the stress field that generated them (Fig. 5).

We present a numerical test to prove this hypothesis, using a cluster of 34 events all with ten first-motion polarities. The theoretical polarities of the events are generated using the same focal mechanism solution, with strike $=121^{\circ}$, $\operatorname{dip}=37^{\circ}$, and rake $=-66^{\circ}$. The locations of the stations on the focal sphere are determined randomly by generating random numbers. For example, the numbers from 1 to 100 are used for epicentral distances from 1 to $100 \mathrm{~km}$, and these in turn are used to estimate the take-off angles. Similarly, the random numbers from 1 to 360 are generated for their azimuths. Thus, the locations of the stations on the focal sphere are randomly determined. The ten-polarity events in our data set mostly do not include stations beyond an epicentral distance of $100 \mathrm{~km}$. We generated several data sets with different maximum epicentral distances that vary from 25 to $200 \mathrm{~km}$. Using the method of Horiuchi et al. (1995), we inverted the randomly generated 340 first-motion polarity data sets to simultaneously determine the stress tensor and the faulting parameters of the 34 events. The results are shown in Fig. 6, which shows the locations of the $P$ - and $T$-axes of the derived focal mechanisms along with the $P$ and $T$-axis locations of the focal mechanism that was used to generate the polarity data sets. The fluctuation of the estimated $P$ - and $T$-axis around the actual $P$ - and $T$-axis is due to the bias in the estimated focal mechanism parameters, as shown in Fig. 7. Although the theoretical focal mechanism is not precisely obtained from the ten-polarity 


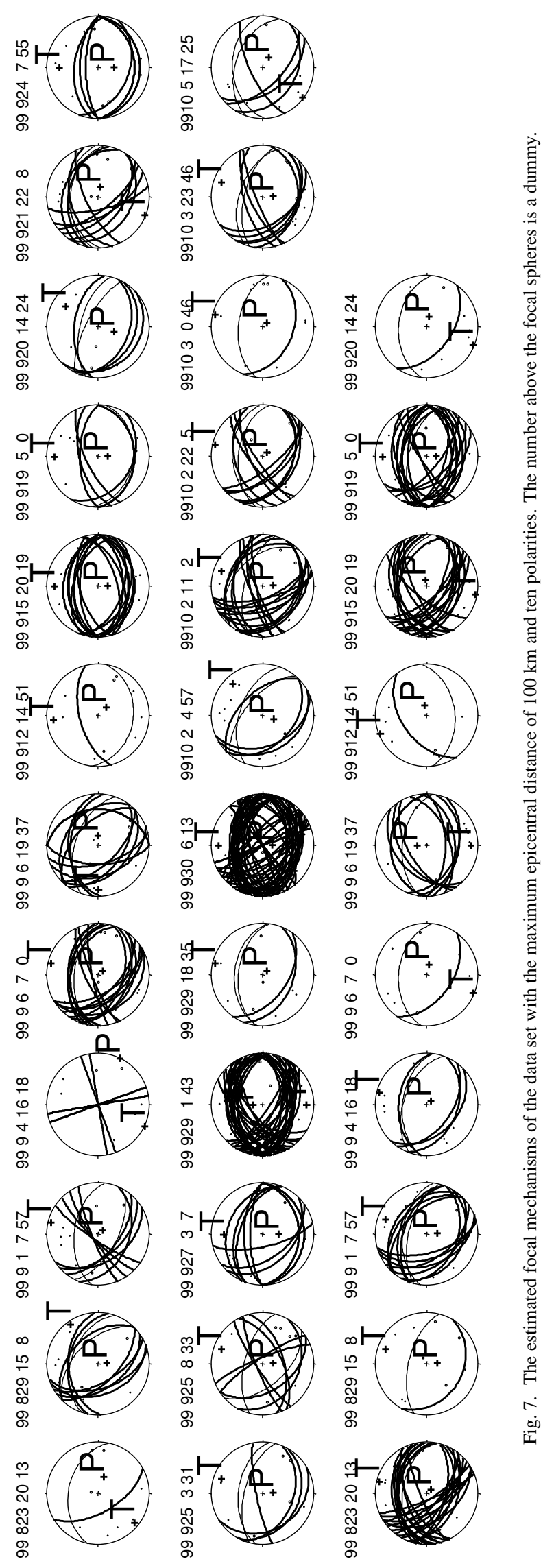



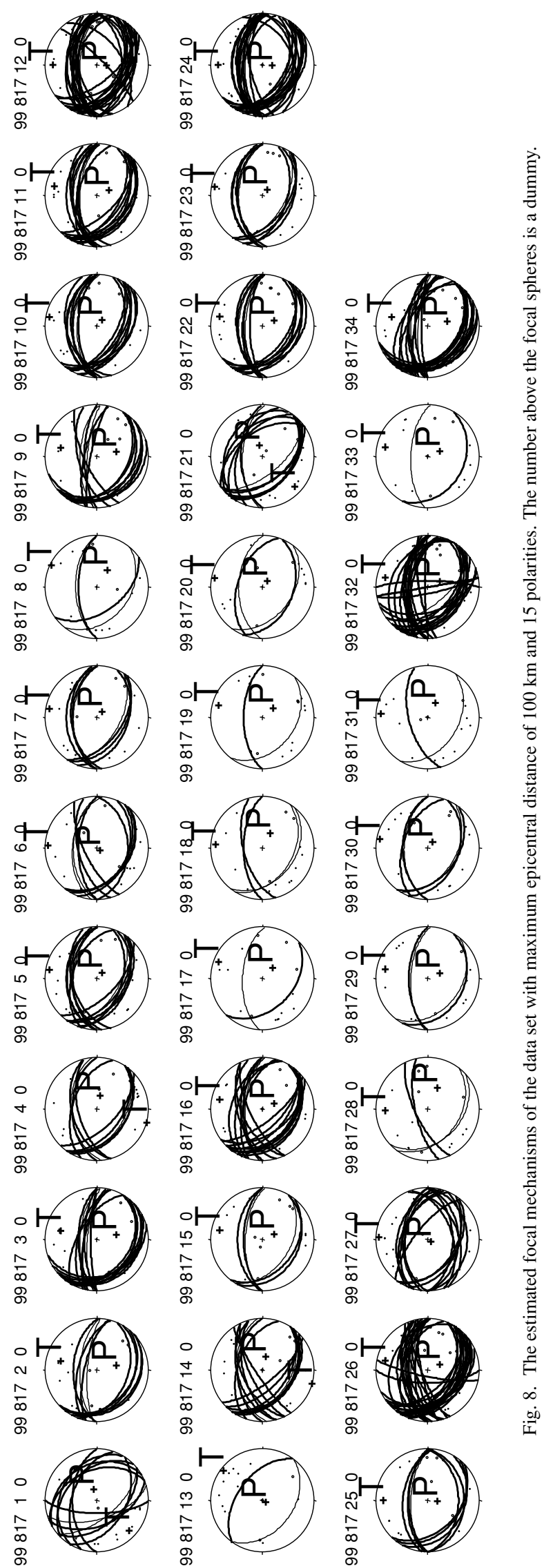
Table 1. Stress tensor inversion results using aftershock rst-motion polarities and the regional stress tensor derived from the fault plane solutions of large events which occurred between 1943 and 1999. The locations of the clusters labeled with capital letters A-G are shown in Fig. 1. The total number of aftershocks in a cluster, the number of events used to determine the local stress tensors, and the total number of polarities in these clusters are also given. $\sigma_{1}, \sigma_{2}$, and $\sigma_{3}$ denote the maximum, intermediate, and minimum principal compressive stress axes, while $\phi$ and $\delta$ show the azimuth and plunge of these axes in degree, respectively. The plunge is measured from horizontal. $R$ is the ratio of the principal stress amplitudes de ned as $R=\left(\sigma_{2}-\sigma_{1}\right) /\left(\sigma_{3}-\sigma_{1}\right)$, where $\sigma_{1} \geq \sigma_{2} \geq \sigma_{3}$. Min and Max are the minimum and maximum number of polarity mis ts in the clusters obtained for a $5^{\circ}$ grid search.

\begin{tabular}{|c|c|c|c|c|c|c|c|c|c|c|c|}
\hline \multirow{2}{*}{$\begin{array}{l}\text { Aftershock } \\
\text { clusters }\end{array}$} & \multirow{2}{*}{$\begin{array}{c}\text { Used/Total events } \\
(545 / 758)\end{array}$} & \multirow{2}{*}{$\begin{array}{l}\text { Polarity } \\
\text { (counts) }\end{array}$} & \multicolumn{2}{|c|}{$\sigma_{1}$} & \multicolumn{2}{|c|}{$\sigma_{2}$} & \multicolumn{2}{|c|}{$\sigma_{3}$} & \multirow[t]{2}{*}{$R$} & \multicolumn{2}{|c|}{ Polarity mis ts } \\
\hline & & & $\phi$ & $\delta$ & $\phi$ & $\delta$ & $\phi$ & $\delta$ & & Min & Max \\
\hline $\mathrm{A}$ & $88 / 111$ & 1008 & 268 & 46 & 117 & 40 & 194 & 15 & 0.50 & 84 & 187 \\
\hline B & $61 / 68$ & 729 & 312 & 30 & 57 & 24 & 180 & 50 & 0.65 & 32 & 108 \\
\hline $\mathrm{C}$ & $50 / 55$ & 622 & 282 & 15 & 196 & 15 & 328 & 69 & 0.35 & 29 & 79 \\
\hline $\mathrm{D}$ & $93 / 112$ & 1297 & 284 & 24 & 154 & 55 & 25 & 24 & 0.36 & 56 & 218 \\
\hline$E$ & $32 / 43$ & 426 & 5 & 65 & 286 & 5 & 198 & 25 & 0.33 & 25 & 60 \\
\hline $\mathrm{F}$ & $167 / 309$ & 2351 & 348 & 52 & 222 & 25 & 118 & 27 & 0.83 & 101 & 341 \\
\hline $\mathrm{G}$ & $54 / 60$ & 703 & 347 & 55 & 94 & 11 & 191 & 33 & 0.50 & 28 & 76 \\
\hline \multicolumn{3}{|c|}{ Regional stress tensor } & 308 & 3 & 91 & 86 & 218 & 2 & 0.50 & & \\
\hline
\end{tabular}

data using this method, the locations of the $P$ - and $T$-axes are predicted satisfactorily (Fig. 7). When we increase the polarity number from 10 to 15 , the inversion yields a focal mechanism similar to the "theoretical" one (Fig. 8).

We compared a set of fault plane solutions determined both with FPFIT and Horiuchi et al. (1995) methods in Fig. 5. Although the $P$ - and $T$-axes of the FPFIT focal mechanisms (Fig. 5(b)) are widely scattered, implying a non-uniform stress eld, the results obtained using the Horiuchi et al. (1995) method (Fig. 5(a)) yield a more uniform distribution.

\section{Results and Discussion}

We have used the rst-motion polarity data of 545 aftershocks from among the 758 recorded by permanent and temporary seismic stations between 17 August and 16 October 1999 (Fig. 4). The minimum of ten rst-motion polarities and the toleration of one mis t polarity were the criteria for the events to be included in the inversion process. The spatial distribution of aftershocks shows seven clusters with delamination along the 17 August ruptured fault zone, extending from Yalova to Düzce (denoted by capital letters A-G in Figs. 1 and 4). The number of aftershocks and the total number of polarities used to derive a stress tensor for these clusters are given in Table 1 along with the inversion results.

\section{1 Çınarcık cluster (A)}

This cluster extends between Yalova and Ç narc k, marking the activity along a 15- to 20-km-long fault lying at the western rupture termination zone of the August 17, 1999 earthquake (Fig. 1). P nar et al. $(2001,2003)$ identi ed this fault as a normal fault with a strike-slip component and suggested that it was last ruptured by the 1963 Ç narc k event $\left(M_{\mathrm{w}} 6.3\right)$.

A high-resolution velocity image along a pro le that crosses the cluster area depicts a clear high-velocity $\left(V_{p}>\right.$ $6.0 \mathrm{~km} / \mathrm{s}$ ) crustal body around a depth of $5.0 \mathrm{~km}$ (Karabulut et al., 2003). The depth cross-section in Fig. 1 indicates that the hypocenters of most of the aftershocks lie in a zone between 5 and $12.5 \mathrm{~km}$ in depth (Ito et al., 2002). However, the CMT depths of the aftershocks obtained by $\mathrm{P}$ nar et al. (2001, 2003) are shallower than $5 \mathrm{~km}$.
We have also obtained shallower depths for the Ç narc $\mathrm{k}$ activity after relocating the aftershocks. It may actually be confusing to see two different depth distributions for the aftershock activities given in Figs. 1 and 4. The aftershocks in Fig. 1 were obtained by Ito et al. (2002), and those in Fig. 4 are obtained by the relocations performed in this study. It was necessary to perform the relocations because the detailed crustal structure and the depth of the events are two important parameters that de ne the take-off angle, and the latter in turn determines the position of the observed polarity on the focal sphere. In our relocations, we used the crustal structure of Karabulut et al. (2003), which was derived from a long active seismic pro le crossing the source region of the 1999 Izmit earthquake. We believed that this pro le is a well-constrained crustal model for the region. Our relocation results are shown in Fig. 4. The hypocentral distribution of the aftershocks in Fig. 1 is obtained using a crustal model in which the velocity increases with depth following a certain function.

In general, the aftershocks that we used for stress tensor inversion are located at a shallow depth within a crustal zone where $V_{p}$ velocities range from 3.0 to $4.0 \mathrm{~km} / \mathrm{sec}$ ( $\mathrm{g}$ ure 3 of Karabulut et al., 2003). The remarkable features of this cluster are: (1) no co-seismic failures were found associated with the August 17 mainshock; (2) the aftershock activity commenced 2 days after the mainshock, probably triggered by Coulomb failure stress increase (P nar et al., 2001), post-seismic slip (Reilinger et al., 2000), or increased pore pressure (Karabulut et al., 2003); (3) the aftershock activity yields a relatively higher $b$-value (Aktar $e t$ al., 2004).

In our data set, the total number of aftershocks that were recorded at more than ten stations is 111 , and the number of events that satis ed the criterion to be set in stress tensor inversion is 88, including 1008 rst-motion polarities (Fig. 9; Table 1). The principal stress axes and the stress magnitude ratio of the best stress tensor and the $P$ - and $T$ axes of the focal mechanism parameters are shown in Fig. 9 along with the polarity mis $t$ distributions. The lower hemisphere projections of the $P$-axes show an E-W alignment parallel to the trend of the normal fault and to that of the NAFZ, while the $T$-axes are oriented in direction normal 

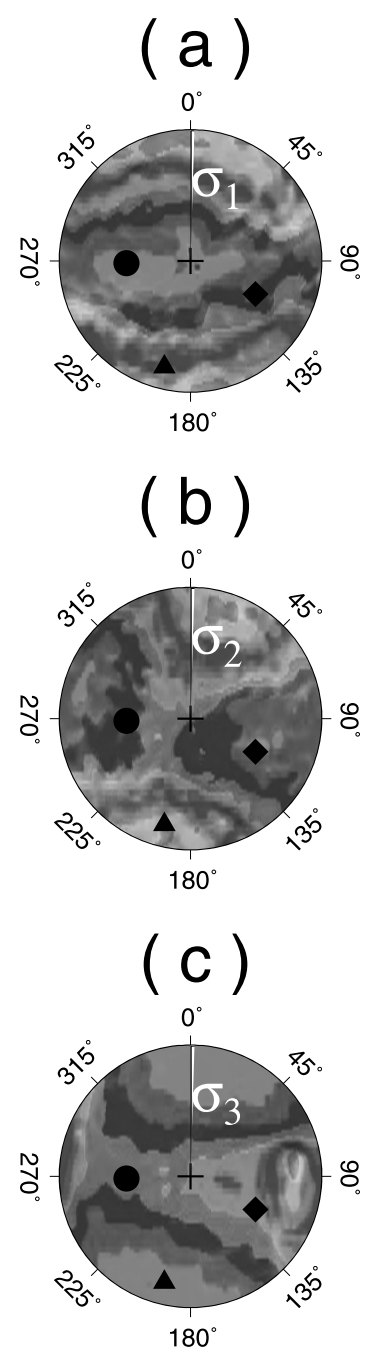

(d)

$0^{\circ}$

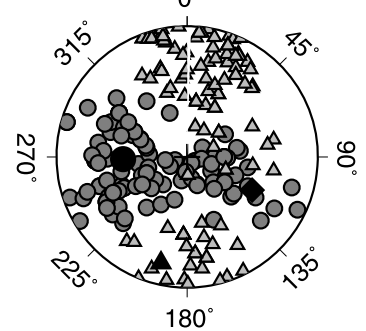

( e )

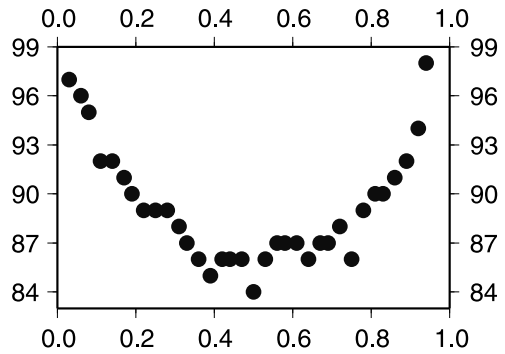

$88 / 1100$

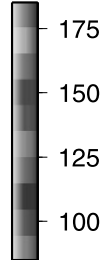

Fig. 9. Stress tensor inversion and fault plane solution results for the Çınarcık cluster. Equal area projection of the number of misfit polarities used to define the orientation of the principal stress axes is shown: (a) the distribution for the maximum compressive stress axis, $\sigma_{1}$, (b) the distribution for the intermediate compressive stress axis, $\sigma_{2}$, (c) the distribution for the minimum compressive stress axis, $\sigma_{3}$, (d) lower hemisphere projection of the $P$ - and $T$-axes of the focal mechanisms determined simultaneously with the stress tensor parameters, (e) the number of misfit polarities versus stress magnitude ratio, $R$. The numbers above the legend indicate the numbers of aftershocks and the total numbers of polarities used in the inversion.

to the fault and to the NAFZ (Fig. 9(d)). The fact that the plunge of the best maximum compressive stress axis $\left(\sigma_{1}\right)$ is away from the horizontal $\left(46^{\circ}\right)$ and the plunge of the minimum compressive stress axis is close to the horizontal $\left(15^{\circ}\right)$ suggests a trans-tensional stress regime. The depth range of the aftershocks used for stress tensor inversion is shallower than $5 \mathrm{~km}$ and has been identified as a low-velocity zone (Karabulut et al., 2003). Thus, most of the aftershocks in this cluster are in a weak zone or on a fault plane with a low coefficient of friction, probably resulting from high heat flow. Here, we should note that the area is a popular tourist site due to its geothermal springs.

Taking into account the fault orientation, we claim that the stress tensor inversion results imply a low coefficient of friction or a weak fault. The basic relation between the orientation of the maximum and minimum principal stress axes, the shear and normal stresses, and the orientation of a fault is defined as follows:

$$
\begin{aligned}
& \sigma_{\mathrm{n}}=\sigma_{1} \cos ^{2} \theta+\sigma_{3} \sin ^{2} \theta \\
& \sigma_{\mathrm{s}}=\left(\sigma_{1}-\sigma_{3}\right) \sin \theta \cos \theta
\end{aligned}
$$

Here, $\sigma_{\mathrm{s}}$ and $\sigma_{\mathrm{n}}$ are the shear and normal stresses, respectively, acting on a fault plane, and $\theta$ is the angle between the fault normal and maximum compressive stress axis (pp. 154, Twiss and Moores, 1992). According to these relations, when the trend of the $\sigma_{1}$ axis is close to the strike of the fault, i.e., $\theta$ is close to $90^{\circ}$, the shear stress acting on the fault plane approaches zero. On the other hand, the ratio between the shear and normal stresses acting on a fault plane is proportional to the coefficient of friction $\left(\mu=\sigma_{\mathrm{s}} / \sigma_{\mathrm{n}}\right)$ of that fault plane (pp. 211, Twiss and Moores, 1992) when the fault slips. Based on this knowledge, the fault parallel trend of the $\sigma_{1}$ axis (fault normal trend of $\sigma_{3}$ axis) suggests a low coefficient of friction on the planes that accommodated the aftershock activity of the Yalova-Çinarcık cluster. Similarly, when the trend of $\sigma_{1}$ axis is perpendicular to the strike of the fault, i.e., $\theta$ is close to $0^{\circ}$, the shear stress acting on the fault plane and the coefficient of friction approaches zero.

Very high aftershock activity on this fault commenced on 19 August, i.e., 2 days after the mainshock (more precisely, approximately $63 \mathrm{~h}$ after the mainshock). This length of 

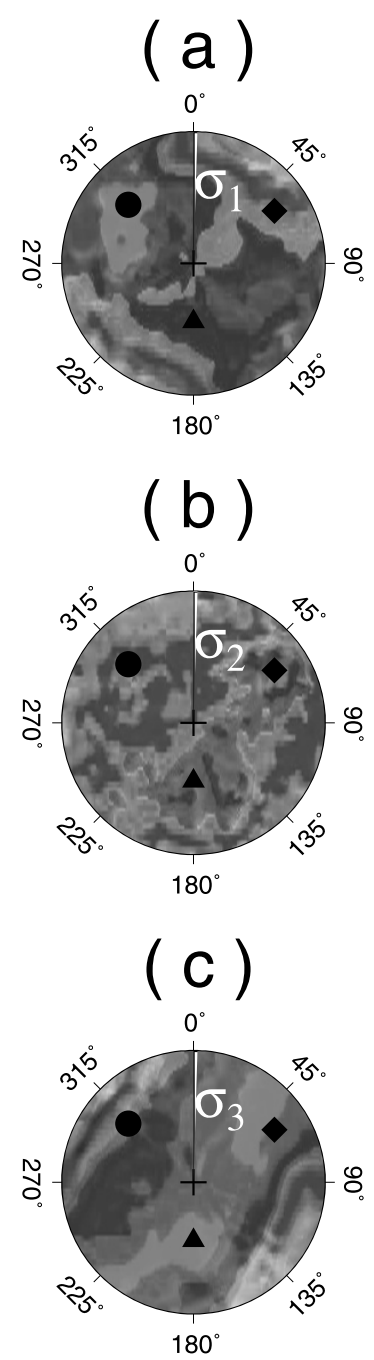
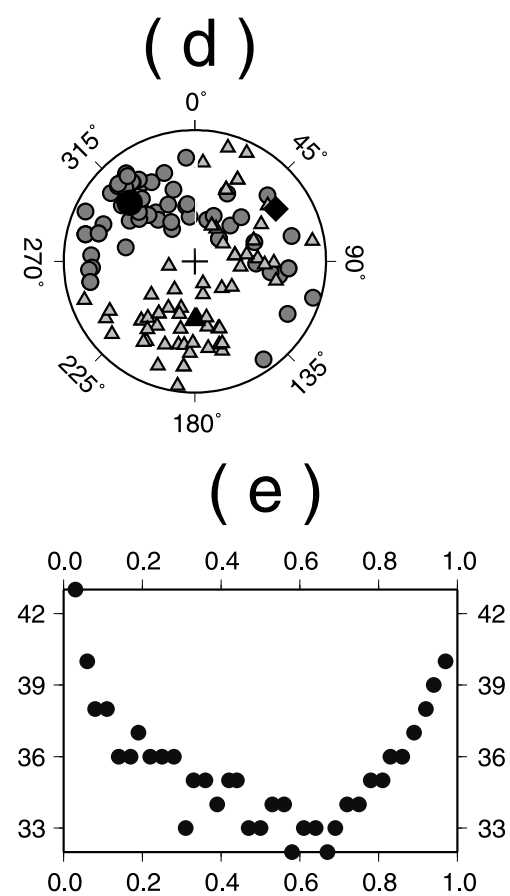

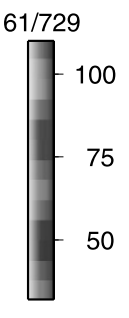

Fig. 10. Stress tensor inversion and fault plane solution results for the Yalova cluster. For a more detailed explanation, see the caption for Fig. 9.

time along with the observation of the extremely low coefficient of friction may be considered to be additional clues on the extent of the co-seismic rupture and the post-seismic dynamics. The debate on whether the Yalova segment (40km-long fault extending between Yalova and the Hersek Peninsula) was ruptured on 17 August is still underway (Cormier et al., 2006). Taking into account the proximity of the Çinarcık and Yalova segments and the low friction coefficient on the Çınarcık segment, the 63-h delay in the appearance of aftershocks may indicate the absence of considerable co-seismic displacements on the Yalova segment and that stress loading by post-seismic displacement was the likely trigger of the activity of the Çınarcık swarm.

\subsection{Yalova cluster (B)}

The lack of primary surface ruptures on the Hersek Delta (e.g. Barka et al., 2002; Gülen et al., 2002) and the presence of aftershock activity along the Yalova segment (Ito et al., 2002; Özalaybey et al., 2002) triggered a debate on the western extension of the fault ruptures associated with the 1999 Izmit earthquake. Pinar et al. (2001) pointed out that the aftershock activity to the west of the delta may have been triggered by the static stress changes associated with the main shock rather than the activity on a ruptured fault. However, coseismic GPS data require at least a 0.6-m slip (Fig. 1) on the fault segment (Reilinger et al., 2000), and even higher displacements $(1.5 \mathrm{~m})$ are inferred from modeling the InSAR data (Wright et al., 2001).

Although the narrow aftershock alignment extending 40$50 \mathrm{~km}$ implies a nearly E-W right-lateral strike slip motion, the fault plane solutions of the aftershocks on this segment are of various types and orientations. Nakamura et al. (2002) obtained mainly reverse faulting mechanisms, while the results of Karabulut et al. (2002) show reverse, strikeslip, and normal faulting mechanisms. The aftershock activity on this segment yields low $b$-values (Aktar et al., 2004). The 3-D crustal structure studies of Barış et al. (2005) and Nakamura et al. (2002) reveal somewhat contradictory images for the Yalova segment; the former shows stronger upper and weaker lower crust and the latter weaker upper crust.

Some workers regard the area between the Gemlik Bay and the Gulf of Izmit as the Armutlu-Almacik Highland and it developed due to compressional tectonic regime (figure 2 in Elmas and Gürer, 2004). If this is this case, the Yalova segment is its northern boundary. In addition, high-resolution seismic and multi-beam bathymetry data acquired in the Gulf of Izmit indicate several compressional features along the Yalova segment occurring as restraining 

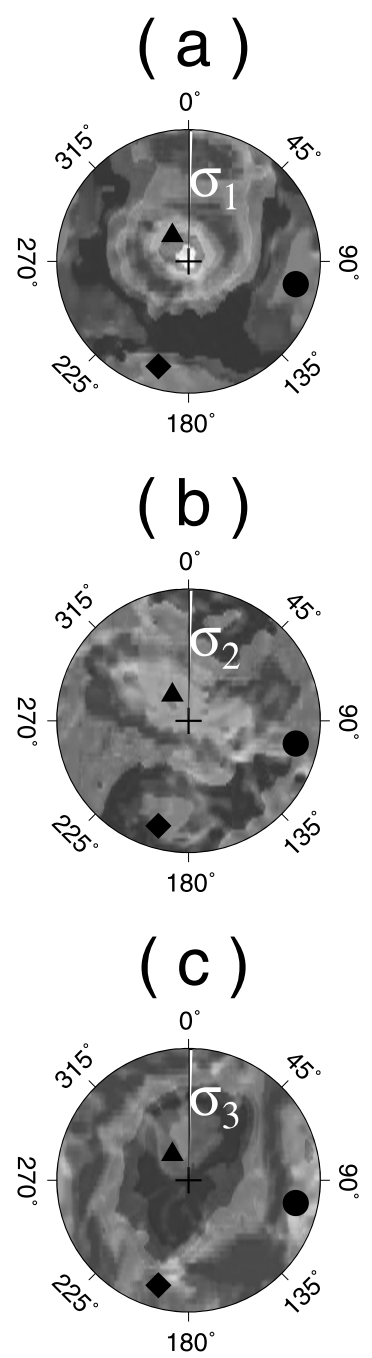

(d)

$0^{\circ}$

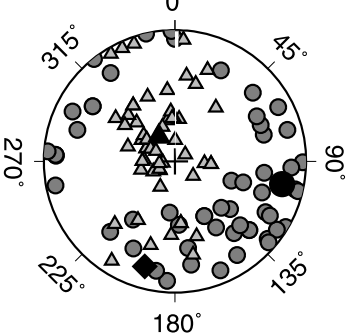

( e )

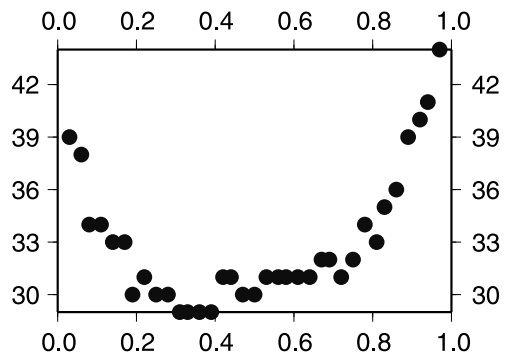

Fig. 11. Stress tensor inversion and fault plane solution results for the Gölcük cluster. For a more detailed explanation, see the caption for Fig. 9.

bends created by a step-over of strike slip faults (Gökaşan et al., 2001).

For the Yalova segment, 61 aftershocks out of 68, including 729 first-motion $P$-wave polarities, met the criterion to be used for stress tensor inversion (Table 1). The inversion results show that the maximum and intermediate principal stress axes are closer to horizontal and that the minimum compressive stress axis is closer to vertical, indicating a transpressive tectonic stress regime (Table 1) in the western part of the Gulf of Izmit, which well fits the structural models (Gökaşan et al., 2001; Cormier et al., 2006).

The trend of the $\sigma_{1}$ axis derived from the aftershocks of the Yalova segment is very close to the azimuth of the maximum compressive stress axis acting prior to the 1999 İzmit mainshock (Fig. 10). This result suggests that the coseismic slip associated with the 17 August event caused no considerable stress perturbations in the western part of the Gulf. This could be due to negligible or lack of co-seismic slip on the Yalova segment.

\subsection{Gölcük cluster (C)}

The August 17, 1999 Izmit mainshock rupture initiated at the eastern end of the Gölcük segment at a depth of about $17 \mathrm{~km}$ (Barış et al., 2002; Ito et al., 2002; Matsushima et $a l ., 2002)$ and propagated westward along the Gölcük seg- ment and eastward along the Sapanca segment (Yagi and Kikuchi, 2000). An approximately 10-km-long aseismic zone between the Yalova and Gölcük segments is observed in the aftershock distribution map (Fig. 1) that could be either due to an arrest of westward rupture propagation by a barrier on a fault plane or a decrease in Coulomb failure stress (Pinar et al., 2001). Although Lettis et al. (2002) suggested that the right step over of the Gölcuik segment to the Yalova segment forms the 5-km-wide Karamürsel basin where the westward rupture propagation was arrested, the study of Gökaşan et al. (2001) suggests that the region is a restraining bend where young sediments are squeezed. Moreover, the fault plane solutions of the aftershocks on this segment determined by Nakamura et al. (2002) show a thrusting mechanism, while different types of mechanisms are estimated by Özalaybey et al. (2002). Also, the central portion of the segment shows relatively higher $b$-values than the tips of the segment (Aktar et al., 2004). The higher $b$-values on the segment correlate with the relatively higher seismic velocities (Nakamura et al., 2002; Barış et al., 2005). Right-lateral strike-slip surface displacements of a maximum of $5.5 \mathrm{~m}$ were measured at Gölcük on this segment (Aydın and Kalafat, 2002; Gülen et al., 2002). GPS data also show that the maximum displacements occurred 
on this segment (Reilinger et al., 2000). The Gölcük segment and the Sapanca segment form a releasing step-over where the vertical displacement of $2.4 \mathrm{~m}$ was observed on a NW-SE-trending normal fault (e.g., Barka et al., 2002).

In our data set, 50 aftershocks out of 55 have none or one mis $t$ polarity. A total of 622 rst-motion polarities are used to derive a stress tensor and focal mechanisms of the aftershocks, and the best stress tensor is determined with 29 mis t polarities (Fig. 11; Table 1). The plunges of the maximum and intermediate compressive stress axes are close to horizontal, and the plunge of the minimum compressive stress axes is close to vertical (Fig. 11). This result is similar to that obtained from the aftershocks on the Yalova segment denoting transpressive tectonic regime (Fig. 10). The main difference between the two sets of results is the $30^{\circ}$ counterclockwise rotation of the stress tensor derived from the aftershocks on the Gölcük segment (Table 1). The relatively lower $P$-wave velocity and little to no coseismic displacements on the Yalova segment and the relatively higher $P$ wave velocity and large coseismic displacements observed on the Gölcük segment are other noticeable differences. This velocity structure, which re ects the strength of the crust, and the coseismic rupture pattern may have played a role in the signi cant rotation of the stress eld inferred from the aftershocks on the Gölcük segment. This subject will be discussed in more detail in the following subsection.

Thus, up to this point in our study, we have obtained transpressive local stress tensors for the two clusters of aftershocks. It is obvious from the studies of Gökaşan et al. (2001) and Cormier et al. (2006) that the source of the compressive component in the stress eld could also be structural, emerging from the restraining zones created by segmentation and offset of right-lateral strike slip faults beneath the Gulf of Izmit.

\subsection{Izmit cluster (D)}

Although the observed surface ruptures of the Sapanca segment are trending E-W, the aftershock distribution in the proximity of Izmit shows ENE-WSW alignment (Fig. 1). We therefore name this swarm activity as Izmit. The hypocenter of the 1999 Izmit earthquake is located in this cluster where swarm activity had been taking place for decades prior to the mainshock. This swarm activity could have been either an indication of seismic activity around an asperity to be ruptured (Honkura et al., 2000; Öncel and Wyss, 2000) or aseismic slip below the hypocenter (Reilinger et al., 2000). The ENE-WSW alignment, which indicates a considerable rotation from the E-W-trending NAFZ, is likely to be a result of high coseismic displacements to the west $(\sim 5.5 \mathrm{~m})$ and to the east $(\sim 5 \mathrm{~m})$ of the segment. Large displacements on strike-slip faults generate large Coulomb failure stress changes that are comparable to the amplitude of the background regional stresses along and at the tips of fault segments that rotate the optimally oriented fault planes (King et al., 1994). An alternative explanation is that the NNE-WSW alignment could be a seismic activity triggered by the mainshock on hidden faults although no faults with these orientations are known.

$P$-wave tomography studies (Nakamura et al., 2002; Bar ş et al., 2005) and the resistivity structure inferred from pro les crossing the Izmit cluster (Elmas and Gürer, 2004;
Oshiman et al., 2002; Tank et al., 2005) indicate that the fault zone in the swarm area is relatively weaker than its surroundings. This situation may explain the observed relatively lower coseismic surface displacements (Nakamura et al., 2002). Tank et al. (2005) point out that this swarm activity took place in the boundary zone between the highresistive and low-resistive materials corresponding to strong and weak crust, respectively. Compared with the neighboring segments, the displacements on this segment were smaller (Ayd n and Kalafat, 2002; Barka et al., 2002; Gülen et al., 2002). Also, GPS data indicate that the small surface rupture displacements were compensated for to some extent by large post-seismic slip observed on and beneath the coseismic rupture zone (Reilinger et al., 2000; Bürgmann et al., 2002; Hearn et al., 2002).

The stress tensor inversion results are given in Table 1 and illustrated in Fig. 12. The minimum mis t polarity region for maximum compressive stress axis $\left(\sigma_{1}\right)$ covers a large area of plunge angles, which is contrary to the horizontal $\sigma_{1}$ prior to the mainshock. The trend of the minimum mis $t$ polarity region for $\sigma_{1}$ (Fig. 12(a)) is similar to the trend of $P$-axes (Fig. 12(d)). Similarly, the lower hemisphere projection of the location of the minimum mis t polarity region of $\sigma_{3}$-axis (Fig. 12(c)) coincides with the lower hemisphere projections of the $T$-axes (Fig. 12(d)).

McKenzie (1969) showed that the orientation of the maximum principal compressive stress axis relative to the orientation of the $P$-axis can differ signi cantly for the cases when the earthquakes occur as a rupture in a homogenous medium or as a slip on pre-existing fault planes. In the case of slip on pre-existing fault planes, the $\sigma_{1}$ direction must be in the quadrant containing the $P$-axis, but it may be at a right angle to the direction of the $P$-axis; however, for the case of rupture of homogenous material, $\sigma_{1}$ may lie in a plane containing the $P$-axis. McKenzie (1969) explains the latter situation using examples of intermediate and deep earthquakes taking place in Tonga-Fiji and Kermadec regions where the $P$-axes of the events are almost parallel to the dip of the subducting slab, where $\sigma_{1}$ is in the plane containing the earthquakes and is directed along the dip of the slab.

Actually, the ENE-WSW orientation, i.e., the counterclockwise rotation of the Izmit segment, emerged after the mainshock. No faults with this orientation are known for the region. As was mentioned earlier, such an orientation may show rotation of the optimally oriented fault planes due to high stress changes associated with the mainshock (King et al., 1994). Also, the stress tensor derived from the Izmit cluster is approximately $15-20^{\circ}$ counterclockwise rotated relative to the regional stress tensor existing prior to the mainshock. Although the slip amount on the adjacent Gölcük fault segments is twofold higher than that of the Izmit segment, we do not observe any rotations in the optimally oriented fault planes as revealed by the aftershock distribution.

Yukutake (2005) investigated spatial changes in the stress eld caused by the large 2000 Tottori earthquake and indicated that the spatial rotation in the stress eld resulting from the static stress changes associated with the mainshock depends on the amplitude of the stress eld prior to the 

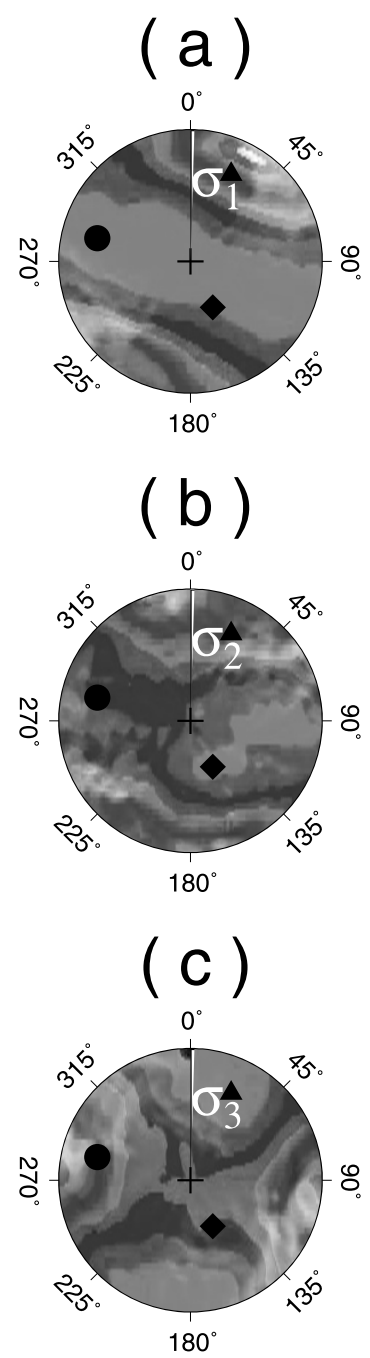

(d)

$0^{\circ}$

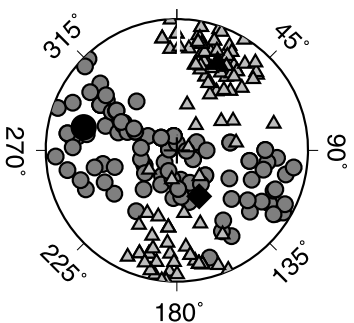

( e )

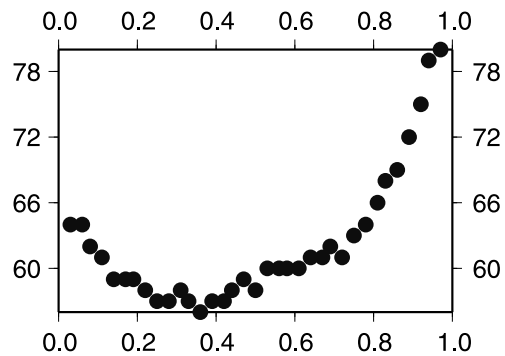

Fig. 12. Stress tensor inversion and fault plane solution results for the İzmit cluster. For a more explanation, see the caption for Fig. 9.

mainshock or the strength of the fault. Where applied initial stress (or fault strength) is high, stress perturbation caused by the mainshock is relatively negligible, and local stress tensor is consistent with regional stress, while in a region under low initial stress (or low fault strength), stress perturbation from the mainshock, relative to the initial stress, is large and the local stress tensor can deviate from the regional stress.

Our results are somewhat explained with the Yukutake (2005) hypothesis. Yukutake simply states that rotation of the stress field by the static stress changes implies a small differential stress amplitude prior to the mainshock and, vice versa, if there is no rotation, the differential stress amplitude prior to the mainshock is large. Furthermore, Yukutake relates the large and small differential amplitudes to strong and weak crustal patches, respectively. Thus, Yukutake's hypothesis implies quite a weak crustal patch for the Izmit region because the low coseismic displacements on this segment may have significantly rotated the optimally oriented fault planes. Similarly, the high coseismic displacements in the Gölcük region and the lack of obvious rotations in the aftershock alignment along the Gölcük segment imply a strong crustal patch for the Gölcük region. These implications also fit the high- and low- velocity zones for Gölcük and Izmit, respectively, obtained by Nakamura et al. (2002).

\subsection{Lake Sapanca cluster (E)}

The Lake Sapanca cluster includes the aftershocks located on the Sapanca segment and the Sapanca step-over basin. The aftershock alignment along the northern shore of the lake depicts the Sapanca segment, while the aftershock on the southern margin of the lake reflects the activity on a fault forming the southern margin of the step-over basin. Bathymetric data acquired after 17 August obviously show that the Sapanca segment is the northern border of the Sapanca basin and extends across Lake Sapanca to the eastern margin of the lake (Lettis et al., 2002). GPS data show that the maximum right-lateral horizontal displacement of 4-5 m observed onshore the Sapanca segment immediately to the west of the lake gradually dies out beneath the lake (Reilinger et al., 2000). During the 17 August event, extensive subsidence occurred along the southern margin of the lake, and 30-cm dip-slip motion on a normal fault was observed (Lettis et al., 2002).

The distribution of the $P$ - and $T$-axes of the focal mechanism of the aftershocks in the cluster indicates that most of the aftershocks have a predominantly normal faulting mechanism where the $P$-axis trend is close to vertical and 

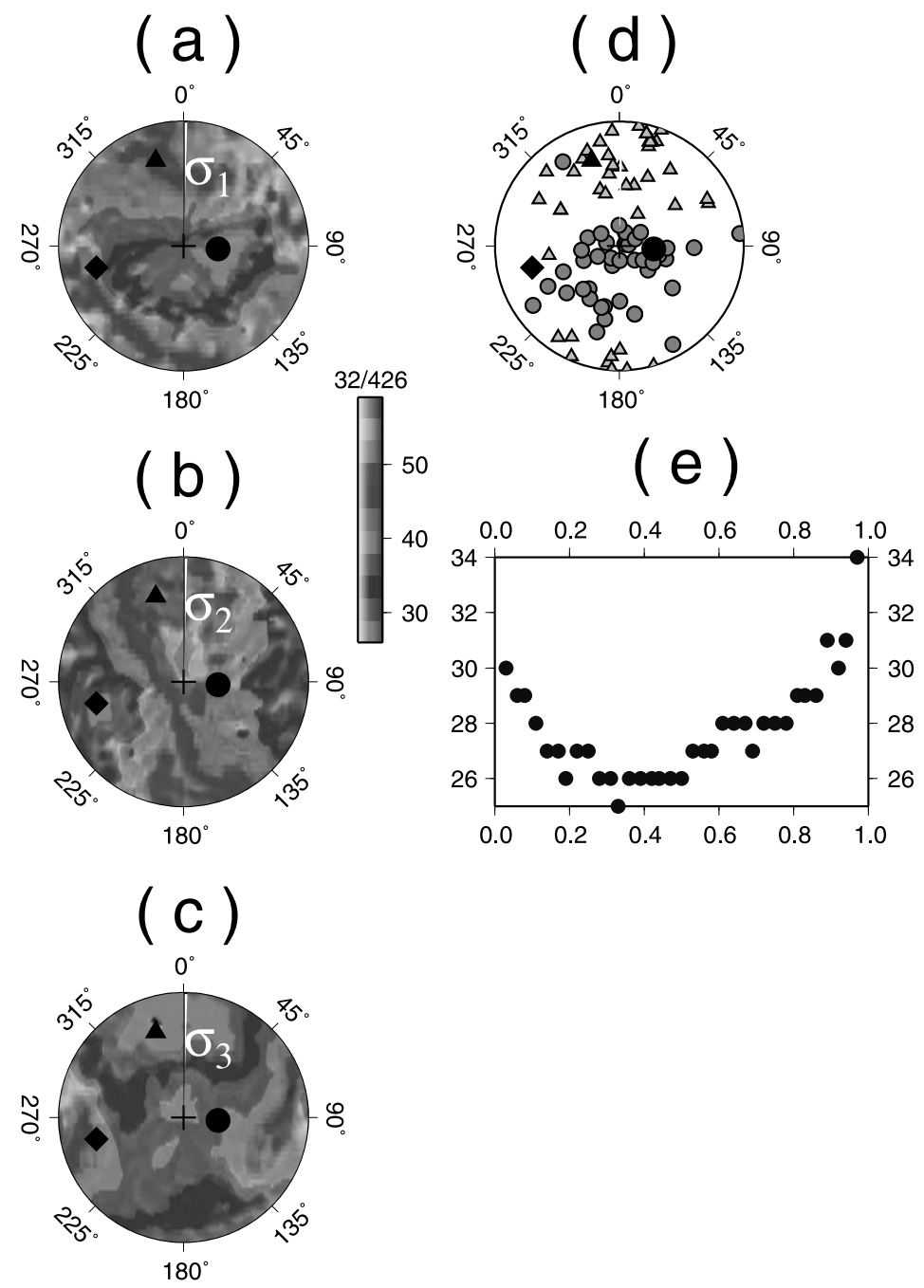

Fig. 13. Stress tensor inversion and fault plane solution results for the Sapanca cluster. For a more detailed explanation, see the caption for Fig. 9.

the $T$-axis trend is close to horizontal (Fig. 13(d)). The stress tensor inversion results (Fig. 13; Table 1) are similar to the results for the Çinarcık cluster, with the maximum compressive principal stress axis parallel to the NAFZ and the minimum compressive stress axis normal to it. Therefore, considering the similar trend of the faults in the two regions, the implications of the stress tensor orientation for the Lake Sapanca region should be similar. The implication of a low friction coefficient for the shallow depth Çınarcık aftershock activity was based on the weak crustal strength at a shallow depth, as revealed by high-resolution seismic imaging (Karabulut et al., 2003). However, the depth range of the Lake Sapanca aftershock activity is between 5 and $15 \mathrm{~km}$, where the crust should be stronger (Fig. 13). Barış et al. (2005) report a relatively stronger crust for this depth range, while Nakamura et al. (2002) suggest a weaker crust.

The low-friction-coefficient implication of the stress tensor for the Lake Sapanca region may reflect the post-seismic slip motion which occurred beneath the lake. Figure 1 shows that the GPS-derived co-seismic displacements are high to the west and east of Lake Sapanca but lower beneath the lake where the swarm lies. The GPS data also show that the post-seismic slips are higher in the region where co-seismic slips were lower (Reilinger et al., 2000;
Bürgmann et al., 2002). Therefore, the fault parallel $\sigma_{1}$ and the fault normal $\sigma_{3}$ derived from the Lake Sapanca swarm may provide some proof of the post-seismic slip motion that is equivalent to the low friction coefficient derived for the Çınarcık swarm. Thus, we have two similar stress tensors resulting from two different effects, implying a low frictional coefficient or weak crust. In truth, the low frictions are not necessarily to be consistent with the post-seismic slip because slip-strengthening is needed for post-seismic slip; therefore, we do not rule out the possibility that the causative agents for the stress tensor derived from Cinarcik and Sapanca swarms are similar.

4.6 Sakarya-Akyazı cluster (F)

Anomalously high aftershock activity took place in this structurally complex Sakarya-Akyazı region (Figs. 1 and 4) where the highest $b$-values were obtained (Aktar et al., 2004). The co-seismic surface ruptures on the 26-km-long Sakarya segment started from $0.5 \mathrm{~m}$ at the eastern margin of Lake Sapanca and increased to a maximum of $5.1 \mathrm{~m}$ just $3 \mathrm{~km}$ away from the lake. The average horizontal displacements on the western, central, and eastern parts of the segment are 4, 2, and $1 \mathrm{~m}$, respectively, gradually dying out eastward. Repeated surface measurements conducted at several sites on the segment show that the sites of low co- 

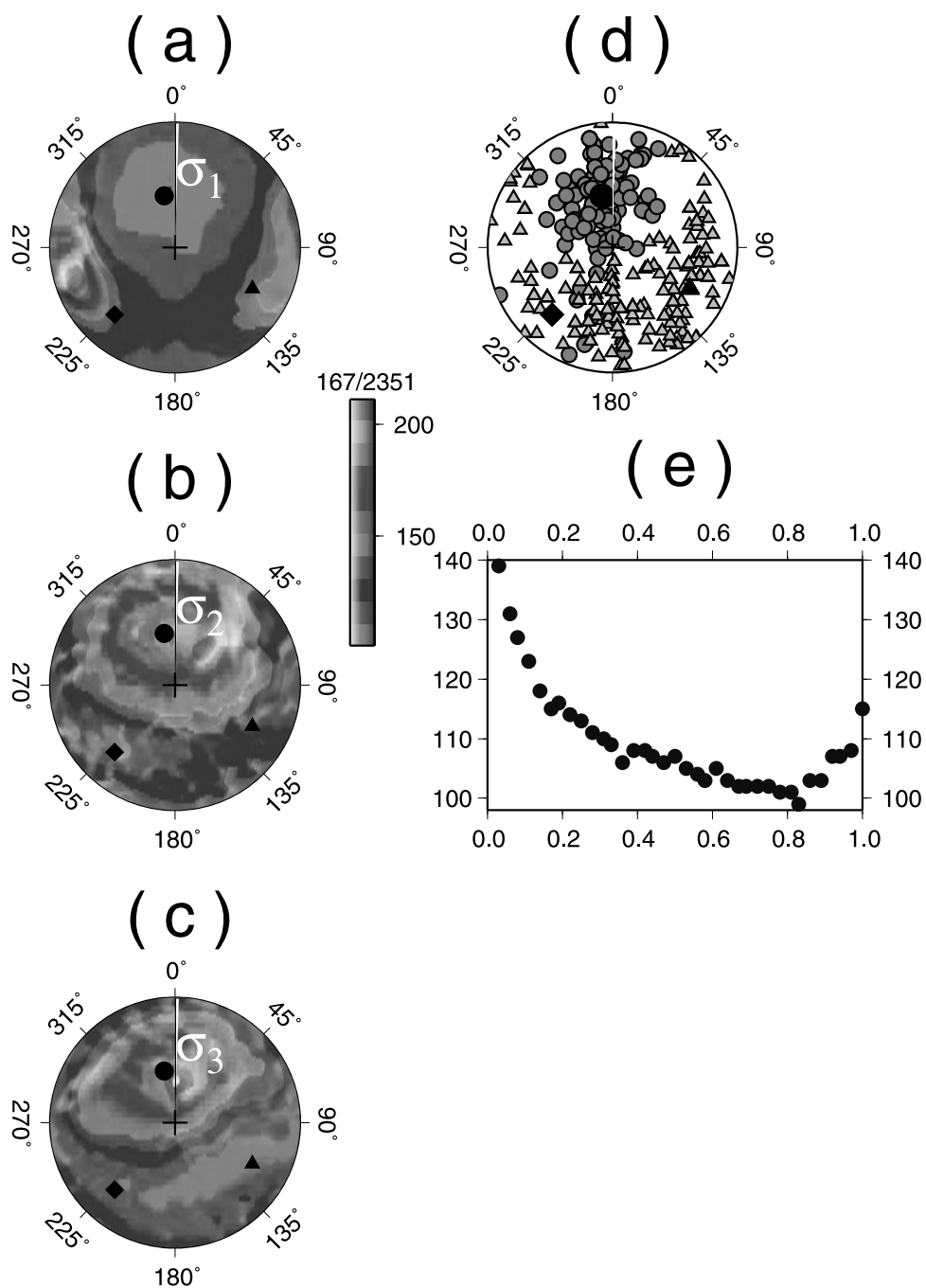

Fig. 14. Stress tensor inversion and fault plane solution results for the Sakarya-Akyazı cluster. For a more detailed explanation, see the caption for Fig. 9.

seismic slip experienced large post-seismic slip (Langridge et al., 2002). The 6-km-wide region between the eastern end of the Sakarya segment and the Karadere segment is a site of no surface ruptures (Barka et al., 2002).

The Sakarya segment forms a releasing bend to the west with the Sapanca segment while the left step-over of the Karadere segment to the Sakarya segment creates a restraining bend around Akyazı (Lettis et al., 2002). Also, the Sakarya segment and the westernmost segment ruptured by the 1967 Mudurnu earthquake form a 6-km-wide releasing step-over basin that arrested the westward propagating ruptures of the Mudurnu earthquake. This earthquake ruptured several segments on the NAFZ (Pınar et al., 1996; Müller and Aydin, 2004).

The data set includes 300 aftershocks in the SakaryaAkyazı cluster for which at least ten first-motion $P$-wave polarity readings are available. We first implemented stress tensor inversion using all of the aftershocks in the cluster. Only 167 events out of 300 met the condition of one misfit polarity to be included in the stress tensor inversion analysis. The results of this inversion process are shown in Fig. 14 and Table 1. We next divided the data set into subsets, considering the fact that the large number of after- shocks that do not meet the criterion to be used in stress tensor inversion is due to spatial or temporal variations in the stress field.

We first handle the case of spatial variation, dividing the data set into two subsets, namely, the western and the eastern subsets. The first data subset includes 180 aftershocks lying in the western half of the cluster, and the second subset includes 120 aftershocks located in the eastern side of the cluster. In the first data subset, 147 aftershocks, including 2,124 first-motion polarities, were used to derive a stress tensor; the inversion results are identical to the stress tensor determined using the whole data set (Fig. 15). The stress tensor inversion of the second data subset was performed using 99 events and 1,335 polarities. The result shows a stress tensor of a similar extensional character but considerably rotated compared to the stress tensor of the first data subset. The trend and plunge of the maximum, intermediate, and minimum compressive stress axes are $113^{\circ}$ and $70^{\circ}, 277^{\circ}$ and $19^{\circ}$, and $8^{\circ}$ and $5^{\circ}$, respectively, and the stress magnitude ratio $R$ equals 0.81 (Fig. 16). As already mentioned, the observed co-seismic displacements were lower and the post-seismic displacements were higher in the eastern part of the Sakarya-Akyazı cluster and, vice versa, the 

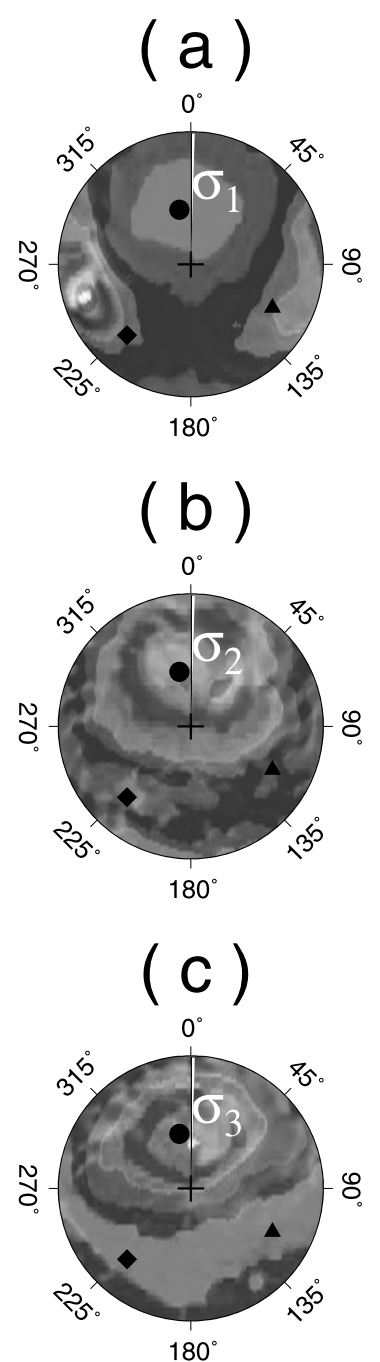

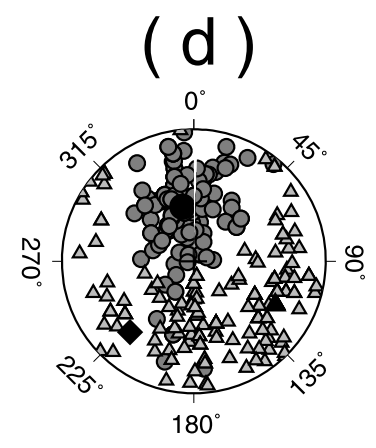

( e )

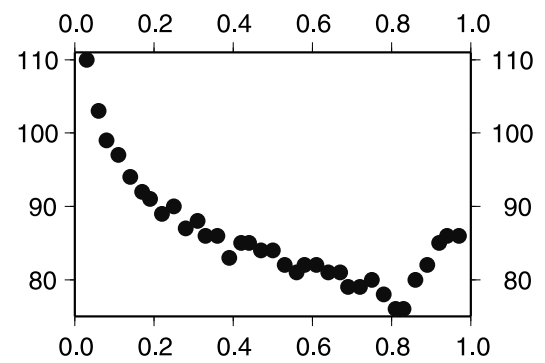

Fig. 15. Stress tensor inversion and fault plane solution results for the western Sakarya-Akyazı cluster. For a more detailed explanation, see the caption for Fig. 9.

co-seismic displacements were higher and the post-seismic displacements were lower in the western part of the cluster (Langridge et al., 2002). These observations are in accordance with the different orientations of the stress field in the eastern and western parts of the cluster. The orientation of the eastern stress tensor and the $\mathrm{N} 75^{\circ} \mathrm{W}$ strike of the Akyazı strand indicate post-seismic slip similar to that for the Sapanca cluster, where post-seismic slip was reported by Langridge et al. (2002), since the $\sigma_{1}$-axis tends to be fault parallel and the $\sigma_{3}$-axis tends to be fault normal.

Although the orientation of the stress tensors derived from the first and second data subsets is different, the transtensional stress regime ( $\sigma_{1}$ close to vertical, $\sigma_{2}$ and $\sigma_{3}$ close to horizontal) and the stress magnitude ratio close to $R=0.8$ are common features (Figs. 14, 15, 16). These stress tensors are somewhat contradictory to the expectation because the Sakarya and Karadere segment forms a restraining bend in the Akyazı region where the compressive stress tensor should be expected. However, when we carefully check the location of the aftershocks, we see that they tend to occur to the south of the restraining bend, i.e., between the rupture zones of the 1967 Mudurnu and the 1999 Izmit earthquakes. Thus, the stress tensors derived from the aftershocks of the 1999 event show that the region between the rupture zones of the northern and southern branches of the NAFZ forms a releasing bend that generates a severalkilometer-wide step-over basin where the sediment thickness reaches up to $10 \mathrm{~km}$ (Tank et al., 2005). The wide and thick sedimentary basin has arrested the westward propagating ruptures of the 1967 Mudurnu earthquake for 32 years. In contrast, the eastward propagating ruptures of the Sakarya segment were able to cross the basin and trigger a 1- to 1.5-m slip on the Karadere segment (Langridge et al., 2002; Müller and Aydın, 2004).

Let us now discuss this asymmetry of rupture propagation during the 1967 and 1999 major earthquakes. One possible explanation could be the large difference in the amount of deformation accumulated on the segments that tried to cross the basin in 1967 and 1999. The maximum co-seismic slip on the western part of the segment where the rupture propagated and gradually decreased eastward during the 1999 mainshock event was about $5 \mathrm{~m}$. In comparison, the maximum observed co-seismic slip during the 1967 rupture was about $1.9 \mathrm{~m}$. That is to say, in 1999 the co-seismic slip was strong enough to trigger an eastward slip that propagated through the basin, but in 1967 the ac- 

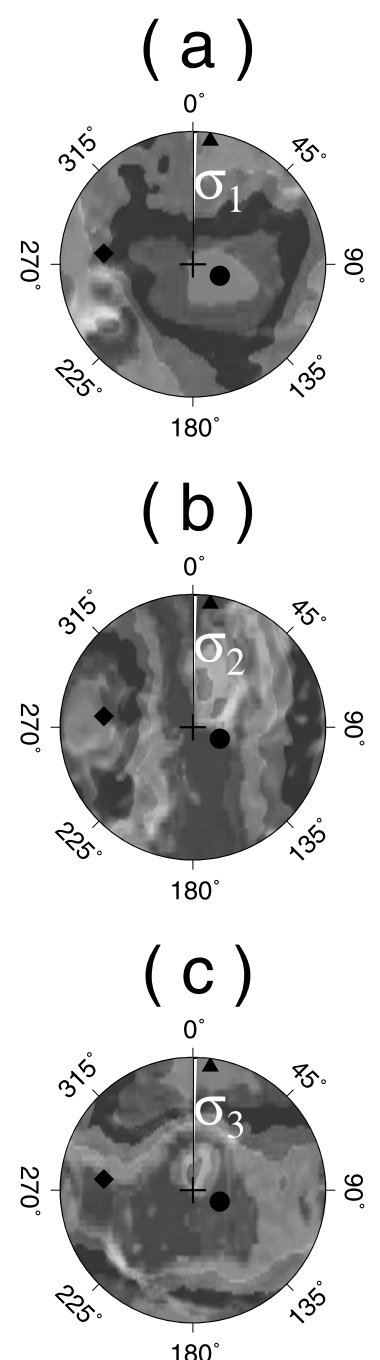

(d)

$0^{\circ}$

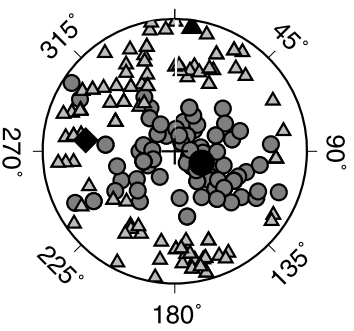

( e )

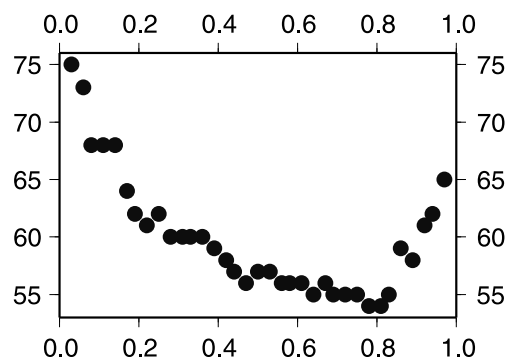

99/1335

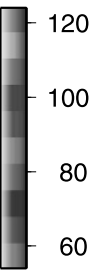

100

80

60

Fig. 16. Stress tensor inversion and fault plane solution results for the eastern Sakarya-Akyazı cluster. For a more detailed explanation, see the caption for Fig. 9.

cumulated strain was not high enough to do the same.

We then divided the period from 17 August 1999 to 10 October 1999 into time intervals of 2 weeks and investigated temporal variation in the stress tensor. The results of timeline analysis were similar to those obtained from our analyses of spatial variations, indicating that transtensional stress regime were dominant at all the time intervals.

\subsection{Karadere cluster $(G)$}

The maximum right-lateral displacement on the ${\mathrm{N} 60^{\circ}-}^{-}$ $70^{\circ}$ E-striking, 35- to $40-\mathrm{km}$-long Karadere segment that is the easternmost ruptured segment was $1.5 \mathrm{~m}$, with an average of $1 \mathrm{~m}$. This value is quite low compared with the measurements on the segments lying to the west of it (Çemen et al., 2000; Aydın and Kalafat, 2002; Hartleb et al., 2002; Lettis et al., 2002). In addition to the low average slip, its oblique orientation to the generally EW-trending NAFZ is another prominent feature of the Karadere segment (Müller and Aydin, 2004).

A couple of weeks after the mainshock, Iio et al. (2002) installed a dense network to monitor the aftershock activity along the Karadere segment. They subsequently obtained seismological evidence for post-seismic slip or creeping along the segment. This occurrence of this aftershock ac- tivity was also evident from the GPS data, indicating that the highest post-seismic slip during the first 80 days after the mainshock occurred beneath the Karadere segment (Reilinger et al., 2000; Bürgmann et al., 2002).

Taking our discussion on the results derived from the Çınarcık, Sapanca, and Sakarya-Akyazı aftershock swarms into consideration, we suggest that the stress tensor inversion results obtained from the aftershocks around Karadere segment (Table 1; Fig. 17) can be attributed to the postseismic slip detected by the previous studies. Contrary to the fault parallel $\sigma_{1}$ and fault normal $\sigma_{3}$ in the previous cases, the $\sigma_{1}$ in the Karadere stress tensor is fault normal and the $\sigma_{3}$ is fault parallel. Despite the differences in the orientations of the $\sigma_{1}$ - and $\sigma_{3}$-axes, both cases imply a low frictional coefficient.

\section{Conclusions}

Spatial variation of the stress field along the fault rupture zone of the Izmit earthquake was investigated by means of stress tensor inversion using first-motion polarity data for seven aftershocks clusters. The summary of our findings are as follows: 

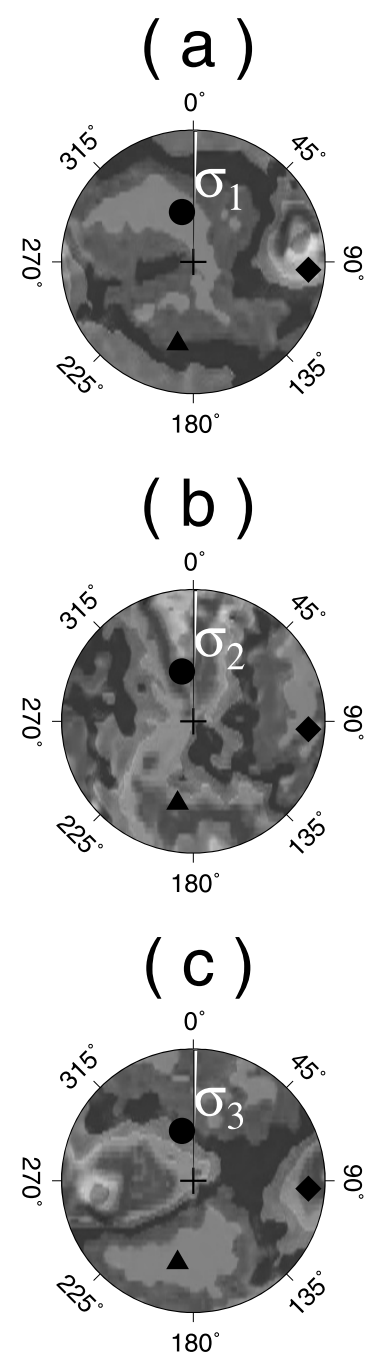
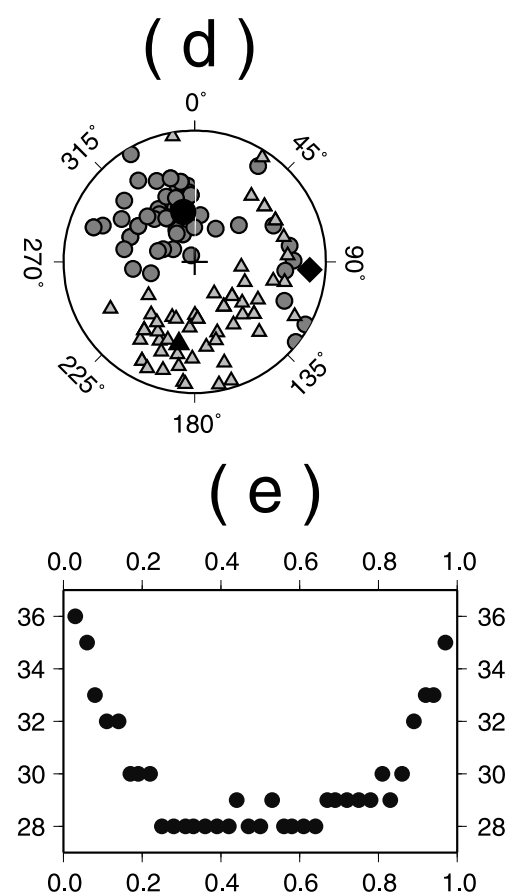

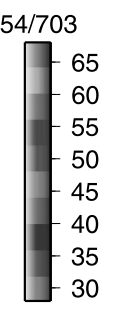

Fig. 17. Stress tensor inversion and fault plane solution results for the Karadere cluster. For a more detailed explanation, see the caption for Fig. 9.

1. The aftershocks in the Çınarcık cluster yield a stress tensor of extensional character. We interpret the fault parallel $\sigma_{1}$ and fault normal $\sigma_{3}$ acting around the Çınarcık fault area as evidence of a low coefficient of friction or weak crust. Such an interpretation is in agreement with the results of other geophysical studies and the high heat flow in the Çınarcık geothermal area.

2. The trend of the $\sigma_{1}$ axis around the Yalova segment is close to the pre-Izmit mainshock trend of the maximum compressive stress axis, implying that the $17 \mathrm{Au}-$ gust event caused no considerable stress perturbations in the western part of the Gulf of Izmit. This suggests negligible or lack of co-seismic slip on the Yalova segment west of the Hersek Peninsula.

3. Although the right step-over of the Gölcuik segment to the Yalova segment forms a 5-km-wide releasing basin east of the Hersek Peninsula where the westward rupture propagation was arrested (Lettis et al., 2002), the stress tensor inversion of the aftershocks shows compressive style of deformation. Similar features are derived from high-resolution bathymetry and shallow reflection data which indicate that the region is restraining at the place where young squeezed sediments are observed (Gökaşan et al., 2001; Cormier et al., 2006;
Okyar et al., 2008). Also, the estimated $20^{\circ}-25^{\circ}$ rotation of the $\sigma_{1}$-axis relative to the regional stress tensor acting prior to the Izmit earthquake should be due to the large co-seismic displacements, which reached up to $5.5 \mathrm{~m}$. On the other hand, the E-W alignment of the aftershocks shows no rotation in the optimally oriented fault planes, implying a strong crust along the segment. The last two facts suggest that the stronger the crust, the higher the accumulated deformation.

4. The stress tensor derived from the Izmit cluster is approximately $20^{\circ}$ counterclockwise rotated relative to the regional stress tensor existing prior to the mainshock. Despite the co-seismic displacements being twofold less than the Gölcük segment, the optimally oriented fault planes in the Izmit area are rotated by about $20^{\circ}$, as revealed by the aftershock distribution. The geophysical studies show that the crust in this part of the fault zone is weak, which in turn suggests a differential stress amplitude that is lower than the co-seismic stress changes, resulting in rotation of the stress field and optimally oriented fault planes. Thus, the weaker the crust, the lower the accumulated strain or stress. 
5. The fault parallel $\sigma_{1}$ and the fault normal $\sigma_{3}$ derived from Lake Sapanca swarm are similar to the stress tensor derived from the Ç narc k swarm, implying a low frictional coef cient. Contrary to the Ç narc k segment, the Sapanca segment experienced post-seismic slip. Thus, the two similar stress tensors are the results of two different effects, both implying a low frictional coef cient or weak crust.

6. We interpret the different orientation of the stress eld in the eastern and western parts of the Sakarya-Akyaz cluster as re ecting different levels of post-seismic displacements observed along the segment. The orientation of the eastern stress tensor and the $\mathrm{N} 75^{\circ} \mathrm{W}$ strike of the Akyaz strand once again indicate fault weakness, i.e., the $\sigma_{1}$-axis tends to be fault parallel and the $\sigma_{3}$-axis tends to be fault normal at the place where post-seismic slip occurred. In addition, the transtensional features of the stress tensors are contradictory to expectation because the Sakarya and Karadere segments form a restraining bend. Here, the stress tensors show that the region between the rupture zones of the northern and southern branches of the NAFZ forms a releasing bend generating a several-kilometerwide step-over basin where the thickness of the sediment reaches up to $10 \mathrm{~km}$ (Tank et al., 2005).

7. Post-seismic slip was detected along the Karadere segment as well in the area where the stress tensor inversion of the aftershocks shows that $\sigma_{1}$ is fault normal and $\sigma_{3}$ is fault parallel.

8. The good correlation between the post-seismic slip regions of the Izmit earthquake and the orientation of the stress tensor is a challenging observation and can be a tool for detecting creeping faults using the focal mechanisms of events taking place along the creeping part of faults.

Acknowledgments. An earlier version of this article was improved with the comments raised by Dr. Shozo Matsumura and an anonymous reviewer. The rst author (A.P.) was a JSPS (Japan Society for the Promotion of Science) fellow when this study was initiated. This work was supported by the Research Fund of the University of Istanbul, project number UDP-3562/09042009.

\section{References}

Aktar, M., S. Özalaybey, M. Ergin, H. Karabulut, M. P. Bouin, C. Tap rdamaz, F. Biçmen, A. Yörük, and M. Bouchon, Spatial variation of aftershock activity across the rupture zone of the 17 August 1999 Izmit earthquake, Turkey, Tectonophysics, 391, 325-334, 2004.

Ayd n, A. and D. Kalafat, Surface ruptures of the 17 August and 12 November 1999 Izmit and Düzce earthquakes in Northwestern Anatolia, Turkey: Their tectonic and kinematic signi cance and the associated damage, Bull. Seismol. Soc. Am., 92, 95-106, 2002.

Bar ş, Ş., A. Ito, S. B. Üçer, Y. Honkura, N. Kafadar, R. Pektaş, T. Komut, and A. M. Iş kara, Microearthquake activity before the Izmit earthquake in the Eastern Marmara region, Turkey (1 January 1993-17 August 1999), Bull. Seismol. Soc. Am., 92, 394-405, 2002.

Bar ş, Ş., J. Nakajima, A. Hasegawa, Y. Honkura, A. Ito, and S. B. Üçer, Three-dimensional structure of Vp, Vs, and Vp/Vs in the upper crust of the Marmara region, NW Turkey, Earth Planets Space, 57, 1019-1038, 2005.

Barka, A., The North Anatolian fault zone, Ann. Tecton., Special Issue, 6 (Suppl), 164-195, 1992.

Barka, A., Slip distribution along the North Anatolian fault associated with large earthquakes of the period of the period 1939-1967, Bull. Seismol. Soc. Am., 59, 521-589, 1996.
Barka, A. A. and K. Kadinsky-Cade, Strike-slip fault geometry in Turkey and its in uence on earthquake activity, Tectonics, 7, 663-684, 1988.

Barka, A., H. S. Akyüz, E. Altunel, G. Sunal, Z. Çak r, A. Dikbaş, B. Yerli, R. Armijo, B. Meyer, J. B. de Chabalier, T. Rockwell, J. R. Dolan, R. Hartleb, T. Dawson, S. Christofferson, A. Tucker, T. Fumal, R. Langridge, H. Stenner, W. Lettis, J. Bachhuber, and W. Page, The surface rupture and slip distribution of the 17 August 1999 Izmit earthquake (M7.4), North Anatolian Fault, Bull. Seismol. Soc. Am., 92, 43-60, 2002.

Bellier, O. and M. Zoback, Recent state of stress change in the Walker Lane zone western basin and Range Province-USA, Tectonics, 14, 564-593, 1995.

Bürgmann, R., S. Ergintav, P. Segall, E. H. Hearn, S. McClusky, R. E. Reilinger, H. Woith, and J. Zcshau, Time-dependent distributed afterslip on and deep below Izmit earthquake rupture, Bull. Seismol. Soc. Am., 92, 126-137, 2002.

Çemen, I., E. Gökten, B. Varol, R. K 1 ç, V. Özaksoy, C. Erkmen, and A. $\mathrm{P}$ nar, Turkish earthquakes reveal dynamics of fracturing along a major strike-slip fault zone, Eos Trans. AGU, 81, 309-313, 2000.

Cormier, M. H., L. Seeber, C. M. G. McHugh, A. Polonia, N. Çagatay, Ö. Emre, L. Gasperini, N. Görür, G. Bortoluzzi, E. Bonatti, W. B. F. Ryan, and K. R. Newman, North Anatolian Fault in the Gulf of Izmit (Turkey): Rapid vertical motion in response to minor bends of a nonvertical continental transform, J. Geophys. Res., 111, B04102, doi:10.1029/2005JB003633, 2006.

Elmas, A. and A. Gürer, A comparison of the geological and geoelectrical structures in the Eastern Marmara region (NW Turkey), J. Asian Earth Sci., 23, 153-162, 2004.

Eyidogan, H., U. Güçlü, Z. Utku, and E. Degirmenci, A Macro-seismic Guide Book for the Large Turkish Earthquakes, Istanbul Technical University, 1991 (in Turkish).

Gephart, J. W. and D. W. Forsyth, An improved method for determining the regional stress tensor using earthquake focal mechanism data: application to the San Fernando earthquake sequence, J. Geophys. Res., 89, 9305-9320, 1984.

Gökaşan, E., B. Alpar, C. Gazioglu, Z. Y. Yücel, B. Tok, E. Dogan, and C. Güneysu, Active tectonics of the Izmit Gulf (NE Marmara Sea): from high resolution seismic and multi-beam bathymetry data, Mar. Geol., 175, 273-296, 2001.

Gülen, L., A. P nar, D. Kalafat, N. Özel, G. Horasan, M. Y lmazer, and A. M. Iş kara, Surface fault breaks, aftershock distribution, and rupture process of the 17 August 1999 Izmit, Turkey, earthquake, Bull. Seismol. Soc. Am., 92, 230-244, 2002.

Hartleb, R. D., J. F. Dolan, H. S. Akyüz, T. E. Dawson, A. Z. Tucker, B. Yerli, T. K. Rockwell, E. Toraman, Z. Çak r, A. Dikbaş, and E. Altunel, Surface rupture and slip distribution along the Karadere segment of the 17 August 1999 Izmit and the western section of the 12 November 1999 Düzce, Turkey, Earthquakes, Bull. Seismol. Soc. Am., 92, 67-78, 2002.

Hearn, E., H. R. Bürgmann, and R. Reilinger, Dynamics of Izmit earthquake postseismic deformation and loading of the Düzce earthquake hypocenter, Bull. Seismol. Soc. Am., 92, 172-193, 2002.

Honkura, Y., A. M. Iş kara, N. Oshiman, B. Üçer, Ş. Bar ş, M. K. Tunçer, M. Matsushima, R. Pektaş, C. Çelik, S. B. Tank, F. Takahashi, M. Nakanishi, R. Yoshimura, Y. Ikeda, and T. Komut, Preliminary results of multidisciplinary observations before, during, and after the Kocaeli (Izmit) earthquake in the western part of the North Anatolian Fault Zone, Earth Planets Space, 52, 293-298, 2000.

Horiuchi, S., G. Rocco, and A. Hasegawa, Discrimination of fault planes from auxiliary planes based on simultaneous determination of stress tensor and a large number of fault plane solutions, J. Geophys. Res., 100(5), 8327-8338, 1995.

Iio, Y., S. Horiuchi, Ş. Bar ş, C. Çelik, J. Kyomen, B. Üçer, Y. Honkura, and A. M. Iş kara, Aftershock distribution in the eastern part of the aftershock region of the 1999 Izmit, Turkey, earthquake, Bull. Seismol. Soc. Am., 92, 411-417, 2002.

Ito, A., S. B. Üçer, Ş. Bar ş, Y. Honkura, A. Nakamura, T. Kono, R. Pektaş, T. Komut, A. Hasegawa, and A. M. Iş kara, Aftershock activity of 1999 Izmit earthquake, Turkey, revealed from mikroearthquake observations, Bull. Seismol. Soc. Am., 92, 418-427, 2002.

Karabulut, H., M. P. Bouin, M. Bouchon, M. Dietrich, C. Cornou, and M. Aktar, The seismicity in the Eastern Marmara Sea after the 17 August 1999, Izmit earthquake, Bull. Seismol. Soc. Am., 387-393, 2002.

Karabulut, H., S. Özalaybey, T. Taymaz, M. Aktar, O. Selvi, and A. Kocaoglu, A tomographic image of the shallow crustal structure in the Eastern Marmara, Geophys. Res. Lett., 30(24), 2277, doi:10.1029/2003GL018074, 2003. 
King, G. C. P., R. S. Stein, and J. Lin, Static stress changes and the triggering of earthquakes, Bull. Seismol. Soc. Am., 84, 935-953, 1994.

Kiratzi, A. A., Stress tensor inversions along the westernmost North Anatolian Fault Zone and its continuation into the North Aegean Sea, Geophys. J. Int., 151, 360-376, 2002.

Langridge, R. M., H. D. Stenner, T. E. Fumal, S. A. Christofferson, T. K. Rockwell, R. D. Hartleb, J. Bachhuber, and A. A. Barka, Geometry, slip distribution, and kinematics of surface rupture on the Sakarya fault segment during the 17 August 1999 Izmit, Turkey, earthquake, Bull. Seismol. Soc. Am., 92, 107-125, 2002.

Lettis, W., J. Bachhuber, R. Witter, C. Brankman, C. E. Randolph, A. Barka, W. D. Page, and A. Kaya, In uence of releasing step-overs on surface fault rupture and fault segmentation: Examples from the 17 August 1999 Izmit earthquake on the North Anatolian fault, Turkey, Bull. Seismol. Soc. Am., 92, 19-42, 2002.

Matsushima, M., Y. Honkura, N. Oshiman, S. Bar ş, M. K. Tunçer, S. B. Tank, C. Çelik, F. Takahashi, M. Nakanishi, R. Yoshimura, R. Pektaş, T. Komut, E. Tolak, A. Ito, Y. Iio, and A. M. Iş kara, Seismoelectromagnetic effect associated with the Izmit earthquake and its aftershocks, Bull. Seismol. Soc. Am., 92, 350-360, 2002.

McClusky, S., S. Balassanian, A. Barka, C. Demir, S. Ergintav, I. Georgiev, O. Gurkan, M. Hamburger, K. Hurst, H. Kahle, K. Kastens, G. Kekelidze, R. King, V. Kotzev, O. Lenk, S. Mahmoud, A. Mishin, M. Nadariya, A. Ouzonis, D. Paradissis, Y. Peter, M. Prilepin, R. Reilinger, I. Sanli, H. Seeger, A. Tealeb, M. N. Toksoz, and G. Veis, Global Positioning System constraints in plate kinematics and dynamics in the eastern Mediterranean and Caucasus, J. Geophys. Res., 105, 5695-5719, 2000.

McKenzie, D. P., The relation betwenn fault plane solution for earthquakes and the directions of the principal stresses, Bull. Seismol. Soc. Am., 59, 591-601, 1969.

Müller, J. R. and A. Ayd n, Rupture progression along discontinuous oblique fault sets: implications for the Karadere rupture segment of the 1999 Izmit earthquake, and future rupture in the Sea of Marmara, Tectonophysics, 391, 283-302, 2004.

Nakamura, A., A. Hasegawa, A. Ito, B. Üçer, Ş. Bar ş, Y. Honkura, T. Kono, S. Hori, R. Pektaş, T. Komut, C. Çelik, and A. M. Iş kara, Pwave velocity structure of the crust and its relation to the occurrence of the 1999 Izmit, Turkey, earthquake and aftershocks, Bull. Seismol. Soc. Am., 92, 330-338, 2002.

Okyar, M., A. Pinar, D. Tezcan, and Z. Kamaci, Late quaternary seismic stratigraphy and active faults of the Gulf of Izmit (NE Marmara Sea), Mar. Geophys. Res., doi: 10.1007/s11001-008-9049-6, 2008.

Öncel, A. O. and M. Wyss, The major asperities of the Mw=7.4 Izmit earthquake de ned by the microseismicty of the two decades before it, Geophys. J. Int., 143, 501-506, 2000.

Oshiman, N., R. Yoshimura, T. Kasaya, Y. Honkura, M. Matsushima, Ş. Bar ş, C. Çelik, M. K. Tunçer, and A. M. Iş kara, Deep resistivity structure around the fault associated with the 1999 Kocaeli earthquake, Turkey, in Seismotectonics in Convergent Plate Boundary, edited by Y. Fujinawa and A. Yoshida, pp. 293-303, Terra Sci. Publ. Company, 2002.

Örgülü, G. and M. Aktar, Regional moment tensor inversion for strong aftershocks of the August 17, 1999 Izmit earthquake (Mw=7.4), Geophys. Res. Lett., 28(2), 371-374, 2001.

Özalaybey, S., M. Ergin, M. Aktar, C. Tap rdamaz, F. Biçmen, and A. Yörük, The 1999 Izmit earthquake sequence in Turkey: Seismological and tectonic aspects, Bull. Seismol. Soc. Am, 92, 376-386, 2002.

P nar, A., Y. Honkura, and M. Kikuchi, Rupture process of the 1992 Erzincan earthquake and its implication for seismotectonics in Eastern Turkey, Geophys. Res. Lett., 21, 1971-1974, 1994.

P nar, A., Y. Honkura, and M. Kikuchi, A rupture model for the 1967 Mudurnu valley, Turkey, earthquake and its implications for seismotectonics in the western part of the North Anatolian fault zone, Geophys. Res. Lett., 23, 29-32, 1996.

P nar, A., Y. Honkura, and K. Kuge, Seismic activity triggered by the 1999 Izmit earthquake and its implications for the assessment of future seismic risk, Geophys. J. Int., 146, F1-F7, 2001.

P nar, A., Y. Honkura, and K. Kuge, Moment tensor inversion of recent small to moderate sized earthquakes: Implication for seismic hazard and active tectonics beneath the Sea of Marmara, Geophys. J. Int., 152, 113, 2003.

Reasenberg, P. A. and D. Oppenheimer, FPFIT, FPPLOT, and FPPAGE: Fortran computer programs for calculating and displaying earthquake fault-plane solutions, U.S. Geol. Surv. Open-File Rep., 85-739, 1985.

Reilinger, R. E., S. Ergintav, R. Bürgmann, S. McClusky, O. Lenk, A. Barka, O. Gürkan, L. Hearn, K. L. Feigl, R. Çakmak, B. Aktug, H. Özener, and M. N. Toksöz, Coseismic and Postseismic Fault Slip for the 17 August 1999, M=7.5, Izmit, Turkey Earthquake, Science, 289, 1519-1524, 2000 .

Sieh, K., L. Jones, E. Hauksson, K. Hudnut, D. E. Philips, T. Heaton, S. Hough, K. Hutton, H. Kanamori, A. Lilje, S. Lindvall, S. F. McGill, J. Mori, C. Rubin, J. A. Spotia, J. Stock, H. K. Thio, J. Trieman, B. Wernicke, and J. Zachariasen, Near- eld investigations of the Landers earthquake sequence, April to July 1992, Science, 260, 171-177, 1993.

Stein, R. S., A. A. Barka, and J. H. Dietrich, Progressive failure on the North Anatolian fault since 1939 by earthquake stress triggering, Geophys. J. Int., 128, 594-604, 1997.

Tank, B., Y. Honkura, Y. Ogawa, M. Matsushima, N. Oshiman, M. K. Tunçer, C. Çelik, E. Tolak, and A. M. Iş kara, Magnetotelluric imaging of the fault rupture area of the 1999 Izmit (Turkey) earthquake, Phys. Earth Planet. Inter., 150, 213-225, 2005.

Twiss, R. J. and E. M. Moores, Structural Geology, W. H. Freeman and Company, New York, 1992.

Utkucu, M., S. Nalbant, J. McCloskey, S. Steacy, and Ö. Alptekin, Slip distribution and stress changes associated with the 1999 November 12, Düzce (Turkey) earthquake (Mw=7.1), Geophys. J. Int., 153, 229-241, 2003.

Wright, T., E. Fielding, and B. Parsons, Triggered slip: observations of the 17 August 1999 Izmit (Turkey) earthquake using radar interferometry, Geophys. Res. Lett., 28(6), 1079-1082, 2001.

Yagi, Y. and M. Kikuchi, Source rupture process of the Kocaeli, Turkey, earthquake of August 17, 1999, obtained by joint inversion of near- eld and teleseismic data, Geophys. Res. Lett., 27, 1969-1972, 2000.

Yukutake, Y., Spatial change in the stress eld around large earthquake faults, PhD Thesis, Graduate School of Sciences, Kyoto University, 2005 .

A. P nar (e-mail: alipinar@istanbul.edu.tr), S. B. Üçer, Y. Honkura, N. Sezgin, A. Ito, Ş. Bar ş, D. Kalafat, M. Matsushima, and S. Horiuchi 